\title{
Cardiovascular Risk Assessment using Arterial Stiffness: A Deep Learning Framework
}

\author{
Shanu $\mathrm{N}^{1}$ and Ganesh Shunmugavel ${ }^{2}$ \\ ${ }^{1}$ College of Engineering Karunagappally \\ ${ }^{2}$ Noorul Islam Centre For Higher Education
}

September 11, 2020

\begin{abstract}
Background: Atherosclerotic cardiovascular disease (CVD) is severe and early-stage detection is crucial. Elevated arterial stiffness observed in childhood atherosclerosis is associated with CVD. Stiffness is an efficient marker of CVD in hypertensives. Assessment of stiffness includes waveform analysis and image-based techniques. Researchers observed several challenges: realtime application, accuracy, operator variability, image quality, scanning procedure, instrument variability and deficiency of standardized procedure in the assessment. Methods: We searched PubMed, Embase and Cochrane online library from inception up to July 2020. Multiple articles on stiffness, pulse wave velocity, assessment and deep learning (DL)-based methods were analysed. Above all, a DL-based technique for assessment of stiffness from cine-loop is proposed. The method includes region of interest (ROI) localisation in multiple frames, segmentation of lumen and parameter estimation. Results: Compared to conventional methods DL provide improved result in lumen diameter and intima-media thickness (IMT) measurements. Using convolutional neural network (CNN), IMT error was $0.08 \mathrm{~mm}$. Further, error using extreme learning machine-autoencoder was $5.79 \pm 34.42 \backslash$ mum. Furthermore, Jaccard index and Dice similarity in fully convolution neural network (FCN) manifested 0.94 and 0.97 for lumen segmentation respectively. Conclusion: This paper focuses on the association of stiffness and atherosclerosis leading to CVD. Success of image-based stiffness estimation depends on the visibility and orientation of arteries, operator experience, intensity variation, shadowing, artefacts, and noise. Traditional methods include transformations to compensate for these challenges. The success of DL-based techniques in segmentation and localisation inspired application in stiffness measurement. DL is used to estimate stiffness from cine-loop.
\end{abstract}

\section{Introduction}

Each year CVD accounted for 17.9 million deaths, worldwide [4]. There was a surge of $\sim 25 \%$ in CVD mortalities from 2000 to 2016 and the majority (85\%) were either due to ischemic heart disease or stroke. Low-and-middle-income countries with sociodemographic index $<0.75$ [5] reported higher CVD death rate [6,7]. Further, years of life lost (YLL) increased in CVD while global trends in total YLL decreased in other diseases [8]. The all-age disability-adjusted life-years (DALY) in CVD soared $6.5 \%$ while age-standardized DALY declined $16.9 \%$ from 2005 to 2015 [9]. Furthermore, financial stress raised incident CVD risk and all-cause mortality in destitute women and single-men [10,11]. The risk is more pronounced in diabetes [12] and hypertension [13]. To summarize, CVDs deteriorates the quality of life both health-wise and financially; it should, therefore, be identified at an earlier stage and treated [5].

Atherosclerosis, the process of narrowing arterial walls, is the underlying reason for CVD [14,15]. Expressed as a thickening on arterial walls, atherosclerosis leads to macrophage accumulation, necrotic core formation, fibrous-cap, and plaque buildup [16]. Plaque accumulates, perhaps, as a result of an inflammatory response owing to the progress in atherosclerosis [16]. Several complications of atherosclerosis; for example, plaque rupture, stenoses, obstruction to blood flow and embolism, lead to severe conditions in CVD [17]. Atherosclerosis appearing in early childhood and young are linked to CVD and remain silent (asymptomatic) 
for several years [18-20]. However, early-stage detection can prevent disease progression by suitable lifestyle modification and medical intervention [17]. Several studies have observed in the literature that arterial stiffness (or stiffness) and carotid intima-media thickness (IMT) are indicators of atherosclerosis from inception [21-23].

Arterial stiffness describe the rigidity of arterial walls (or loss of elasticity); is age-dependent [21], and augment as atherosclerosis progress [24-27]. Several pathological changes involved in the development of atherosclerosis are instigated in stiffness and both often coexist. Note that mature adults with depression had augmented IMT and stiffness values [28]. Further, arterial stiffness leads to elevated blood pressure [29-32] and in hypertensives, augmented stiffness indicate atherosclerotic CVD [33]. Importantly, elevated stiffness is associated with atherosclerotic cardiovascular events (CVE) [34], stroke [23,35], diastolic heart failure [33], hypertension [29,30,36], diabetes [37,38], obesity [39-41] and renal disease [42,43].

Several indices, pulse pressure (PP), compliance (C), distensibility (D), pulse wave velocity (PWV), Young's modulus, augmented index (AIx), $\beta$-stiffness and Cardio-ankle vascular index (CAVI) are applied for the quantification of arterial stiffness. PP is the difference between systolic and diastolic pressure. Compliance is often described as the ratio of change in volume to change in pressure $\left(C=\underline{\Delta^{\circ}}\right.$

greekP), and distensibility is viewed as the compliance per original volume $\left(D=\frac{C}{V}\right)[44]$. A brief description of various stiffness indices used in clinical studies is provided in Appendix A .

PWV, the most significant measure owing to its association with CVE, is defined as the velocity of pressure, diameter or flow-velocity wave. Often significant variation in elasticity and impedance is observed in arteries from proximal to peripheral [45]. This variation leads to amplification, reflection and change in wave shape along the vasculature attributed to composition, distending pressure, and muscle-tone of the arterial wall [46] [45][47] [48]. Further, the wave shape is dependent on age group [44,49,50], ageing [51,52], physical fitness $[53,54]$, insulin produced [55,56], heart rate, body demographics and gender [57-59]. In short, pulse wave is indicative of hypertension [60], diabetes [56,61,62], aortic disintegration and heart failure [57,63]. From this point of perspective, the assessment of PWV is a promising approach for predicting atherosclerotic CVD.

Assessment of PWV includes invasive and non-invasive techniques. However, non-invasive techniques are popular owing to its clinical application. Clinically, PWV is estimated as the ratio of the distance between two points in distal arteries and time taken by the wave to cover this distance [64]. Based on the methodology used, non-invasive assessment techniques are either "two-site" (regional) or "one-site" (local). The two-site method includes traditional "foot-by-foot" method [64] while the one-site method requires multiple variables for assessment. Studies observed that branchial-ankle PWV (ba-PWV) and carotid-femoral PWV (cfPWV) are highly correlated with significant methods used in the assessment of PWV [65]. Acceptance of any particular method for clinical purposes was debated earlier [46,65]. However, cfPWV is considered "gold standard" due to its strong association with CVD [37,43] and recommendation by various committees [66]. Several challenges owing to the unstandardised nature of assessment are discussed in a later section. Further, $80 \%$ of the measured value of cfPWV and $10 \mathrm{~m} / \mathrm{s}$ cutoff value is accepted clinically [67]. The one-site method includes image-based techniques that involve localisation and segmentation of the lumen region. Performance of these techniques depends on the appearance of the artery in a frame, operator experience, and equipment variability. However, machine learning algorithms proved efficient in localisation and segmentation of lumen and intima-media complex (IMC).

Machine learning systems extract patterns from raw-data and perform specific tasks. These systems are supervised or unsupervised based on the availability of labelled data [68]. During training, data is presented to the system and it produces an output vector based primarily on input and weights. An objective function measures error between the output vector and the target vector (desired output) [69]. The system then updates the weights to minimize this error [69]. This technique is repeated for small sets of data until the mean of the objective function stops decreasing [69]. Further, test-data is used to assess performance on a generalized data and validation is done for optimization [69]. The inspiration behind the application of DL framework is to obtain human-like perfectness in tasks like segmentation, object identification and 
classification. The application of DL in various types of applications, such as lumen characterisation, tumour segmentation and cell detection, has been a motivation for its application on the carotid artery [70].

Major deep learning architectures include the recurrent neural networks (RNN) [69], convolutional neural network (CNN) [69], deep belief networks (DBN) [70] and autoencoders [71,72]. RNN is a network wherein, the output of one layer is connected to the next layer. Partial outputs are applied as feedback along with the next input [69]. RNN is applied in speech and handwriting recognition. The key disadvantage is the problem of vanishing gradients observed in the backpropagation algorithm. Likewise, CNN is applied in object identification and classification. The hidden layer in CNN includes stacks of convolution layers, nonlinear activation layers and pooling layers [69]. Moving from the input layer, the first few layers extract low-level features (edges) and "deeper" layers extract high-level features specific to the object [69]. This network is often trained using backward propagation [69]. Further, DBNs are applied in image and video recognition tasks. DBN utilizes unsupervised learning, based on the restricted Boltzmann machine (RBM) [70]. RBM is a two-layered network wherein the first (input) is called the visible layer and the second is called the hidden layer. In DBN, several RBMs are stacked: hidden layer of one RBM is connected to the visible layer of second RBM and so on. Each RBM is independently trained using unsupervised learning and backpropagation network is applied at the end layers [70]. Likewise, autoencoders also learn features from raw data in an unsupervised manner. This method offers efficient dimensionality reduction and denoising capability. Herein, unlabeled inputs are represented (encoded) using the most important features and the original image (input image) is reconstructed from the encoded image. Different types of autoencoders in practice are convolutional autoencoder, deep autoencoder and contractive encoder. The most important challenge faced by DL-based systems is the limited dataset. However, success using transfer learning methods have motivated research in using other methods, such as reinforced learning and autoencoders. Even so, DL architectures suffer due to overfitting and underfitting. Overfitting occurs when DL architecture gets trained to features more than what is required and underfitting is when too little data is provided, and the system is not modelled accurately. There are several methods that are effectively applied to surmount underfitting and overfitting.

This review summarizes state-of-the-art techniques used for the assessment of arterial stiffness. The article is organized into five main sections: Section 2. will begin by describing conventional techniques of PWV assessment and Section 3. will provide an insight into image-based techniques. Besides, Section 4. will investigate the application of DL-based systems in clinical diagnosis and the last section will discuss stiffness computation using DL-framework.

\section{Search methodology}

A systemic search on Google scholar, Medline, Science Direct and Cochrane database resulted in 58042 studies. The search terms used were "Arterial stiffness", "Pulse wave velocity", "cardiovascular risk assessment", "intima-media thickness", "lumen diameter", "deep learning " and "convolutional neural network". Figure 1. shows the trend on articles from 2000 to 2021 for arterial stiffness. Further, our team focused on peer-reviewed journals and filtered the list for stiffness measurement using image-based techniques. Major research journals were included while other studies were categorized and 145 studies were finalized for this review.

\section{Conventional techniques in PWV assessment}

Waveform-based techniques applied flow velocity, pressure or diameter waves for PWV assessment [73]. Techniques utilized either two-site (Figure 2.) or one-site method for PWV estimation [44]. The former method includes evaluation of flow velocity at two distinct sites separated by a measurable distance and the latter applied either Moens-Korteweg (Eq. 1) [74-77] or Bramwell-Hill equation (Eq. 2) [78].

$$
\mathrm{PWV}=\sqrt{\frac{Y_{m} \cdot \mathrm{h}}{2 \cdot r \cdot \rho}}
$$


where $Y_{m}$ is Young's modulus, $\mathrm{h}$ is the IMT, $r$ is the lumen radius and $\rho$ is the blood density.

$$
\mathrm{PWV}=\sqrt{\frac{\Delta P}{\Delta^{\prime} \cdot \rho}}=\sqrt{\frac{1}{\rho \Delta}}
$$

where $\Delta ?$ is the pressure change, $\Delta \mathrm{V}$ is the volume change and $\mathrm{D}$ is the distensibility coefficient.

Herein, simultaneous measurement of two variables is essential for example, pressure and flow velocity (Doppler) or pressure and diameter (wall tracking). These are further investigated in Section 3. of this paper. A significant two-site method such as velocity-encoded MRI includes transit time [73], flow-area [79], and cross-correlation techniques [80]. In this method, flow pulses are measured at dual sites over multiple cycles and ensemble averaging are employed for accurate results. Further, specific devices employed pressure/displacement waves for PWV estimation; for example Complior [81], SphygmoCor [82,83], PulsePen [84]. However, these devices use manual external tape measurements and therefore, error prone.

Additionally, consumption of meals [85], caffeine [86], and/or cigarette [87] influenced arterial stiffness.

\section{Image-based methods of stiffness computation}

Image-based stiffness computation involves three stages: 1) segmentation of the lumen and IMC 2) estimation of lumen diameter (LD) and IMT, and 3) computation of Young's modulus (or $\beta$-stiffness and Peterson's modulus). Algorithms used for segmentation of lumen and IMC are of two types: boundary-based and region-based. Boundary-based (edge-based) approaches include methods that applied Hough transform [88], snake algorithm [89], active contours [90], and level-sets [91]. However, information about the intensity and curvature of the artery is required before initialisation of contour and energy functions [92]. Region-based methods involve split-and-merge algorithms that include watershed [93], region splitting, region merging [94] and graph-based approaches [95]. Concisely, based on operator intervention splitting, these algorithms are either semi-automatic or automatic. Moreover, a few techniques process multi-frame while others process a single frame. After segmentation of the ROI, estimation of LD and IMT is done using distance measurement techniques such as mean-absolute distance or polyline distance. The final stage of stiffness computation includes the application of Eq. 1 or Eq. 2.

\section{1 Segmentation of lumen region and assessment of lumen diameter}

Lumen is the area between the lumen-intima (LI) boundary of the near-wall (LI-near) and far-wall (LIfar). The distance between LI-near and LI-far is defined as lumen diameter (LD) whereas the gap between intima and media is labelled as IMT. Figure 3. shows a longitudinal segment of the common carotid artery (CCA) and the delineation of LI and MA boundaries. Characterization of the lumen is primary for the assessment of LD and IMT. However, lumen recognition is challenging because of variability in dataset, plaque composition-and-morphology, arterial structure, presence of stenosis, jugular vein and importantly the imaging standards [96,97]. Algorithms applied several theories to overcome these challenges. The most

prominent assumptions are that (a) the brightest boundary corresponds to media-adventitia (MA) edge, and (b) the arterial blood flow is laminar [88]. These theories aid in identifying the edges and ROI. In previous studies of Sifakis et al. [98], statistical estimates were used for automatic recognition of lumen, both in multi-frame and single frame. The success rate was $99 \%$ and the algorithm was effective even in the presence of plaques and moderate amounts of "mimicking arteries" [98]. Surprisingly, the algorithm failed in images with poor far-wall representation and sharp arterial curvature [98]. Over the years, an enormous amount of work was done on automated lumen characterization. Araki et al. [88] used automated ROI detection, spectral analysis and K-means classifier for lumen characterization. The algorithm performed well (Dice similarity 1 ) but was susceptible to noise, motion artefacts and presence of plaque. Molinari et al. [99] suggested a novel approach for seed point selection followed by curve fitting and classification. The method was successful in $92 \%$ cases except in the presence of backscattering and plaque [99]. Most algorithms in the past preferred straight vessels in the frame for better segmentation. Kumar et al. [100] 
applied spatial transformation for pre-processing (straightening curved vessels) and scale-space for boundary segmentation. Dice similarity and Jaccard index were 94.2, 89.1and 93.9, 88.6 respectively on two different sets of GT. Carvalho et al. [95] used contrast-enhanced ultrasound along with the B-mode ultrasound to overcome motion artefacts and noise. Further, joint-histogram and graph-based methods were employed for segmentation. The authors informed segmentation error as the average root mean square error (RMSE) of $112 \pm 73 \mu \mathrm{m}$ compared with the expert recording on two datasets [95]. Rocha et al. [101] used a linear-Bayes classifier along with dynamic programming (DP) for segmentation on 199 images. The authors reported a success rate of $99.5 \%$ and robustness to shadowing, scanner variability and plaque irregularity [101]. Further, reviews on a comparison between different segmentation approaches are presented elsewhere [102]. Table I. summarizes benchmarking studies on lumen segmentation and LD assessment.

Table I. Benchmarking studies on lumen segmentation and LD assessment.

\begin{tabular}{|c|c|c|c|c|}
\hline Study & Method & Dataset \& size & Measures & Findings \\
\hline Sifakis et al. [98] & $\begin{array}{l}\text { Vertical intensity } \\
\text { profile based signal } \\
\text { selection, segment } \\
\text { filtering, Statistical } \\
\text { methods for lumen } \\
\text { centre point } \\
\text { identification }\end{array}$ & $\mathrm{N}=2149(100)$ & $\begin{array}{l}\mathrm{SR}=100 \% \text { Mean } \\
\mathrm{FC}=95.76 \pm 9.61 \% \\
\text { Error }=0.43 \pm 0.26 \\
\mathrm{~mm}\end{array}$ & $\begin{array}{l}\text { CCA recognition in: } \\
\text { poor image quality, } \\
\text { presence of plaque, } \\
\text { jugular vein, } \\
\text { intensity variations } \\
\text { and moderate } \\
\text { arterial curvature }\end{array}$ \\
\hline Araki et al. [88] & $\begin{array}{l}\text { Spectral analysis for } \\
\text { peak detection, } \\
\text { K-means classifier }\end{array}$ & $\mathrm{N}=404(202)$ & $\begin{array}{l}\text { DS 1, JI=92.1 } \\
\text { Mann-Whitney } U= \\
63,356.5 \text { Mean } \\
\text { error, PoM } \\
\text { Cross-correlation } \\
\text { SSI }\end{array}$ & $\begin{array}{l}\text { Segmented result } \\
\text { close to GT. } \\
\text { Consistent LD } \\
\text { assessment. } \\
\text { Automated and } \\
\text { manual results are } \\
\text { consistent if } \\
\text { SSI }>40 \% \text {. } \\
\text { Susceptible to noise, } \\
\text { motion artefacts } \\
\text { and noise. }\end{array}$ \\
\hline Molinari et al. [99] & $\begin{array}{l}\text { Geometric feature } \\
\text { extraction, Line } \\
\text { fitting, classification }\end{array}$ & $\mathrm{N}=200$ & $\begin{array}{l}\text { mean distance } \\
\text { errors } \pm \text { SD in } \\
\text { near-wall }=1.05 \pm \\
1.04 \text { pixels in far } \\
\text { wall } 2.68 \pm 3.94 \\
\text { pixels }\end{array}$ & $\begin{array}{l}\text { Automatic } \\
\text { delineation of CCA. }\end{array}$ \\
\hline Kumar et al. [100] & $\begin{array}{l}\text { Vertical spectral } \\
\text { analysis to trace } \\
\text { adventitial border } \\
\text { Spatial } \\
\text { transformation to } \\
\text { straighten curved } \\
\text { vessels. Scale-space } \\
\text { segmentation. }\end{array}$ & $\mathrm{N}=404(202)$ & $\begin{array}{l}\text { DS and JI were } 94.2 \\
(89.1) \text { and } 93.9 \\
(88.6) . \text { Mean LD } \\
\text { error }=0.27 \pm 0.25 \\
\text { mm Mean IAD } \\
\text { error }=0.24 \pm 0.24 \\
\text { mm }\end{array}$ & $\begin{array}{l}\text { Delineation lumen } \\
\text { and adventitial } \\
\text { borders even in } \\
\text { curved vessels. } \\
\text { Validated with } \\
\text { expert readings }\end{array}$ \\
\hline Carvalho et al. [95] & $\begin{array}{l}\text { Centreline } \\
\text { estimation, } \\
\text { Graph-based } \\
\text { segmentation using } \\
\text { DP. }\end{array}$ & $\begin{array}{l}\mathrm{N}=21(17): 2 \\
\text { datasets of size } 11 \\
\text { and } 10\end{array}$ & $\begin{array}{l}\text { Dataset } 1(\mathrm{RMSE}= \\
191 \pm 43 \mu \mathrm{m}) \text { and } \\
\text { Dataset } 2(\mathrm{RMSE} \\
351 \pm 176 \mu \mathrm{m}) \\
\text { carotids. }\end{array}$ & $\begin{array}{l}\text { Both contrast } \\
\text { enhanced-US and } \\
\text { B-mode were used } \\
\text { for lumen } \\
\text { segmentation. }\end{array}$ \\
\hline
\end{tabular}




\begin{tabular}{lllll}
\hline Study & Method & Dataset \& size & Measures & Findings \\
\hline Rocha et al. [101] & $\begin{array}{l}\text { Auto ROI, DP to } \\
\text { delineate } \\
\text { longitudinal paths, } \\
\begin{array}{l}\text { Linear Bayes } \\
\text { classifier. }\end{array}\end{array}$ & $\begin{array}{l}\text { N=199 Two } \\
\text { datasets }\end{array}$ & SR=99.5\% & $\begin{array}{l}\text { Real-time } \\
\text { processing, fully } \\
\text { automated. }\end{array}$ \\
\hline
\end{tabular}

\section{2 Segmentation LI-far wall and IMT assessment.}

Although IMT can be assessed at both walls, far-wall is more reliable than the near-wall. Further, farwall IMT is associated with coronary heart disease and mean IMT, especially those measured $1 \mathrm{~cm}$ away from the bulb, is correlated with risk factors $[103,104]$. Previous research has largely overlooked computeraided methods in IMT measurements [105]. Liguori et al. [106] used pattern recognition and edge detection techniques for LI-MA delineation. This semi-automated method reported high-correlation (0.97) with manual methods. Dynamic programming (DP) is a highly optimised search-based method useful for edge detection $[95,101,107]$. However, the method showed limited success in curved vessels. Zhou et al. [108] applied a modified DP for intima-media segmentation. The method was efficient and invariant to the rotation but refrained from IMT estimation. Important studies showed that integrated methods provide a better approximation. Faita et al. [109] applied gradient-based edge detection fused with a robust edge detector ("FOAM") followed by a heuristic search. The algorithm performed well when validated with two expert readings on 150 scans. Further, the authors displayed real-time processing using video of the cardiac cycle and the Bland-Altman plots showed zero inter-observer variability [109].

Another important study by Rossi et al. [110] presented segmentation based on two methods: adventitial delineation using sustain attack filter and intimal delineation using multiscale anisotropic barycentre (MAB). The authors reported a variation of $1.3 \%$ for diameter and $3 \%$ for IMT in 36 recordings. However, accuracy of the technique varied considerably based on probe positioning, patient orientation, artefacts and image quality [110]. Later a more robust method, the Hough transform (HT) often used for the detection of lines and circles, was used for carotid artery segmentation [111]. Golemati et al. [112] applied HT and observed that accuracy and specificity were $>0.96$ for both transversal and longitudinal images of non-atherosclerotic subjects. However, the results depend on plaque, shadow and scanner variation [112]. Some scholars have researched snake-algorithm. Loizou et al. [113], Petroudi et al. [90] and Santhiyakumari et al. [114] used snake-algorithm (active contour) for intima-media segmentation. Despite good results, the method is limited by lengthy processing time and initialization. Destrempes et al. [115] argued that distribution of echogenicity in a vertical strip of pixels is a mixture of three Nakagami distributions related to intima, media and adventitia. The authors then applied maximum-a-posteriori (MAP) estimation and expectationmaximization for segmentation [115].

Molinari et al. and the team proposed several techniques for segmentation and IMT measurement $[116,117]$. The team performed LI segmentation based on local statistics and signal analysis and reported improvement in both LI detection $(+32.3 \% \pm 6.7 \%)$ and IMT measurement $(+43.5 \% \pm 2.4 \%)$ [118]. In another research, the team applied, feature extraction, curve fitting and classification, more suitable for MA segmentation [117]. As stated earlier, the integrated approach improved IMT estimation $(+3.6 \pm 1.4 \%)$ and segmentation efficiency [117]. Both IMT and LD show variations in a cardiac cycle. Tracking these variations in IMT is a serious challenge. Ilea et al. [119] adopted segmentation on a video of the cardiac cycle using a Canny edge detector and adaptive normalisation [119]. Table II review various findings on IMT measurement.

Table II. Benchmarking studies on IMT measurement 


\begin{tabular}{|c|c|c|c|c|}
\hline Study & Method & Dataset \& Size & Measures & Findings \\
\hline Zhou et al. [108] & Modified DP & $\mathrm{N}=200(32)$ videos & $\begin{array}{l}\text { Overall error, Total } \\
\text { time, Bland-Altman } \\
\text { plots }\end{array}$ & $\begin{array}{l}\text { Accuracy improved } \\
\text { when the algorithm } \\
\text { was refined using } \\
\text { snake. }\end{array}$ \\
\hline Faita et al. [109] & $\begin{array}{l}\text { Gradient-based edge } \\
\text { detection }\end{array}$ & $\mathrm{N}=150$ & Bland-Altman plots & $\begin{array}{l}\text { variation in mean } \\
\text { bias } \pm \text { SD of } 0.001 \\
\pm 0.035 . \text { High } \\
\text { accuracy and } \\
\text { real-time } \\
\text { application }\end{array}$ \\
\hline Rossi et al. [110] & $\begin{array}{l}\text { Adventitial } \\
\text { delineation using } \\
\text { sustain attack filter, } \\
\text { intimal delineation } \\
\text { using MAB. }\end{array}$ & $\mathrm{N}=36(12)$ & $\begin{array}{l}\text { Bland-Altman plots, } \\
\text { Measurement error }\end{array}$ & $\begin{array}{l}\text { Intra-observer } \\
\text { variability }=0 \text {, } \\
\text { suitable for clinical } \\
\text { trials, comparison } \\
\text { with synthetic } \\
\text { ultrasound images. } \\
\text { Radiofrequency } \\
\text { envelopes analysed. }\end{array}$ \\
\hline $\begin{array}{l}\text { Golemati et al. } \\
{[112]}\end{array}$ & $\begin{array}{l}\text { Hough transform, } \\
\text { Canny edge } \\
\text { detection. Both } \\
\text { B-mode and } \\
\text { M-mode ultrasound }\end{array}$ & $\mathrm{N}=5$ & $\begin{array}{l}\text { Radial displacement } \\
\text { of ROI }\end{array}$ & $\begin{array}{l}\text { Accurate for } \\
\text { non-stenotic. } \\
\text { Atherosclerotic } \\
\text { plaque affected the } \\
\text { result. }\end{array}$ \\
\hline Loizou et al. [113] & $\begin{array}{l}\text { Snake algorithm } \\
\text { Speckle reduction }\end{array}$ & $\mathrm{N}=100$ & Bland-Altman plots & $\begin{array}{l}\text { intra-observer error } \\
=0.08 \text { Hausdorff } \\
\text { distance }=5.2\end{array}$ \\
\hline Petroudi et al. [90] & $\begin{array}{l}\text { Active contour, } \\
\text { Speckle removal }\end{array}$ & $\mathrm{N}=100$ & $\begin{array}{l}\text { Mean absolute } \\
\text { distance. Polyline } \\
\text { distance. Hausdorff } \\
\text { distance. }\end{array}$ & $\begin{array}{l}\text { Mean absolute } \\
\text { distance error }= \\
0.095 \pm 0.0615 \mathrm{~mm} \text {, } \\
\text { Polyline distance }= \\
0.096 \pm 0.034 \mathrm{~mm} . \\
\text { Hausdorff distance } \\
=0.176 \pm 0.047 \mathrm{~mm} .\end{array}$ \\
\hline $\begin{array}{l}\text { Santhiyakumari et } \\
\text { al. [114] }\end{array}$ & $\begin{array}{l}\text { Active contour } \\
\text { segmentation. } \\
\text { Semi-automatic } \\
\text { ROI identification }\end{array}$ & $\mathrm{N}=10063$ normal & $\begin{array}{l}\text { Coefficient of } \\
\text { variation, Pearson's } \\
\text { CC, Wilcoxon } \\
\text { metric }\end{array}$ & $\begin{array}{l}\text { Inter-method error } \\
=0.09 \mathrm{~mm} \mathrm{CV}= \\
18.9 \%\end{array}$ \\
\hline $\begin{array}{l}\text { Destrempes et al. } \\
{[115]}\end{array}$ & $\begin{array}{l}\text { Expectation } \\
\text { maximisation } \\
\text { algorithm, } \\
\text { Nakagami } \\
\text { distribution }\end{array}$ & $\mathrm{N}=30$ & $\begin{array}{l}\text { Mean distance, } \\
\text { Hausdorff distance }\end{array}$ & $\begin{array}{l}\text { Error in: } \mathrm{LI}=0.46 \\
\mathrm{~mm} \mathrm{MA}=0.41 \mathrm{~mm}\end{array}$ \\
\hline Molinari et al. [117] & $\begin{array}{l}\text { Local statistics. } \\
\text { Integrated approach } \\
\text { (Greedy algorithm). }\end{array}$ & $\mathrm{N}=200$ & $\begin{array}{l}\text { Polyline distance, } \\
\text { Mean system error }\end{array}$ & $\begin{array}{l}\text { Error in: LI }= \\
26.3 \pm 55.6 \mu \mathrm{m} \mathrm{MA} \\
=16.2 \pm 31.3 \mu \mathrm{m} \\
\mathrm{IMT}=83.1 \pm 61.8 \\
\mu \mathrm{m}\end{array}$ \\
\hline
\end{tabular}




\begin{tabular}{lllll}
\hline Study & Method & Dataset \& Size & Measures & Findings \\
\hline Ilea et al. [119] & Unsupervised IMC & 40 and 772 frames & coefficient of & Auto tracking of \\
& video segmentation & & variation, & IMT variations in a \\
& & & Bland-Altman plot & cardiac cycle. \\
\hline
\end{tabular}

MAB: multiscale anisotropic barycentre, CC: correlation coefficient

The segmentation methods are often followed by distance measurement for estimation of LD and IMT. Standard procedures for distance measurement involved three different methods: centre line distance (CLD), polyline distance (PLD) and mean absolute distance (MAD) [120,121].

\subsection{Challenges in image-based methods}

Thus, conventional segmentation methods are either semi-automatic or automatic. Human intervention is required at many stages, for example, ROI selection, seed point and/or contour initialization, and distance evaluation [122]. This leads to additional latency and is often error prone. Further, the curvature of the artery and its orientation impinge on segmentation [122]. Most segmentation algorithms require arteries to be recorded horizontally. Spatial transformations are applied to improve orientation before segmentation [122]. Furthermore, the presence of plaque, plaque irregularity and mimicking arterial structures such as jugular vein complicates the process. Moreover, scanner variability, operator experience, angle of incidence (of ultrasound probe), blood back-scattering, shadowing and ultrasound artefacts add to the conundrum [123]. Application of machine learning and deep learning algorithms provided a competitive edge in this scenario.

\section{DL-based systems in clinical diagnosis}

Several studies observed that DL improved accuracy in diagnosis and clinical assessment. The DL architectures performed well, especially in cardiovascular MRI (CMR), fatty liver disease (FLD) tissue characterization and rheumatic arthritis. Although these are separate areas of medical science where different modalities are used, the success of DL motivates the expansion of its horizon. Moreover, the success of DLbased strategy in anatomical research inspire application in CVD diagnosis and prediction. Schmauch et al. proposed a DenseNet-based supervised learning system for the detection classification of focal liver lesions (FLL) [124]. The authors demonstrated region-of-convergence (ROC) and area under the curve (AUC) scores of 0.935 and 0.916 for lesion detection and classification on 367 ultrasound images [124]. Huynh et al. [125] applied transfer learning for detecting malignant tumours. Features from pre-trained AlexNet were used for training. The network had performance similar to analytical methods $(\mathrm{AUC}=0.81)$ [125]. Hatipoglu et al. performed cell segmentation using three DL-based methods: CNN, DBN and autoencoder. The comparative study reported that CNN and autoencoders outperformed conventional segmentation techniques [126].

Table III Benchmarking deep learning-based studies in clinical diagnosis.

\begin{tabular}{|c|c|c|c|c|}
\hline Study & $\begin{array}{l}\text { Dataset } \\
\text { (Population) }\end{array}$ & Method & Measures & Findings \\
\hline $\begin{array}{l}\text { Bai et al. (2018) } \\
{[127]}\end{array}$ & $\begin{array}{l}\mathrm{N}=4875 \mathrm{UK} \\
\text { Biobank }\end{array}$ & $\mathrm{FCN}$ & $\begin{array}{l}\text { Mean absolute } \\
\text { distance, Hausdorff } \\
\text { distance }\end{array}$ & $\begin{array}{l}\text { Human-like } \\
\text { performance in } \\
\text { evaluating CMR } \\
\text { images. Dice } \\
\text { metric }=0.94(\mathrm{LV} \\
\text { cavity), } 0.88(\mathrm{LV} \\
\text { myocardium) } 0.90 \\
\text { (RV cavity). }\end{array}$ \\
\hline
\end{tabular}




\begin{tabular}{|c|c|c|c|c|}
\hline Study & $\begin{array}{l}\text { Dataset } \\
\text { (Population) }\end{array}$ & Method & Measures & Findings \\
\hline $\begin{array}{l}\text { Wang et al. } \\
\text { (2017) [128] }\end{array}$ & $\begin{array}{l}\mathrm{N}=840(210) \\
\text { mammograms }\end{array}$ & $\begin{array}{l}\text { CNN:10 } \\
\text { convolution layers } \\
\text { and two fully } \\
\text { connected layers }\end{array}$ & $\begin{array}{l}\text { Free response } \\
\text { receiver operating } \\
\text { characteristics } \\
\text { (FROC) analysis. }\end{array}$ & $\begin{array}{l}\text { Two-class } \\
\text { classification } \\
\text { problem to } \\
\text { categorize breast } \\
\text { arterial } \\
\text { calcification } \\
\text { (BAC) pixels and } \\
\text { non-BAC pixels } \\
\text { in mammograms, } \\
\text { a risk marker of } \\
\text { CAD. Calcium } \\
\text { mass } \\
\text { quantification } \\
\text { analysis }\end{array}$ \\
\hline $\begin{array}{l}\text { Jamthikar et al. } \\
(2020)[129]\end{array}$ & $\mathrm{N}=404(202)$ & $\begin{array}{l}\text { ML-based risk } \\
\text { factor classifier }\end{array}$ & $\begin{array}{l}\mathrm{AUC}=0.99(\mathrm{P}< \\
0.001) \text { compared to } \\
\text { conventional }\end{array}$ & $\begin{array}{l}57.14 \% \\
\text { improvement over } \\
\text { conventional } \\
\text { algorithm. PoM } \\
\text { and FoM }=96 \% \text {. } \\
\text { Mean absolute error } \\
<5 \% \text {. }\end{array}$ \\
\hline $\begin{array}{l}\text { Biswas et al. (2018) } \\
\text { [130] }\end{array}$ & $\begin{array}{l}\mathrm{N}=63, \text { Liver US: } \\
36 \text { with FLD, } 27 \\
\text { normal }\end{array}$ & $\begin{array}{l}\text { CNN, SVM, ELM. } \\
\text { Tissue } \\
\text { characterization, } \\
\text { risk stratification }\end{array}$ & $\begin{array}{l}\text { ROC, reliability } \\
\text { index, timing } \\
\text { analysis. }\end{array}$ & $\begin{array}{l}\text { DL: Robustness to } \\
\text { noise, } 100 \% \\
\text { accuracy at } 15 \% \\
\text { cropping of borders. } \\
\text { DL better than } \\
\text { SVM \& ELM }\end{array}$ \\
\hline Kuppili et al. [131] & $\mathrm{N}=63$ & ELM, SVM & $\begin{array}{l}\text { AUC, speed test } \\
\text { validation }\end{array}$ & $\begin{array}{l}96.75 \% \text { accuracy in } \\
\text { ELM, } 89.01 \% \\
\text { accuracy in SVM } \\
\text { AUC } 0.97 \text { and } 0.91 \\
\text { in ELM and SVM, } \\
\text { respectively. Speed } \\
\text { improvement of } \\
40 \% \text { in ELM }\end{array}$ \\
\hline $\begin{array}{l}\text { Hemalatha et al. } \\
\text { [132] }\end{array}$ & $\begin{array}{l}\mathrm{N}=276 \text { MEDUSA } \\
\text { database }\end{array}$ & $\begin{array}{l}\text { Hit-or-miss } \\
\text { transform for } \\
\text { bone-line } \\
\text { segmentation, } \\
\text { Active contour for } \\
\text { localization }\end{array}$ & $\begin{array}{l}\text { Accuracy, precision, } \\
\text { specificity, } \\
\text { sensitivity, ROC }\end{array}$ & $\begin{array}{l}95.02 \% \pm 2.78 \\
\text { accuracy Increase in } \\
\text { true positives from } \\
78.12 \% \text { to } 98.15 \% \text {. } \\
\text { False positives } \\
\text { decreased by } 1.41 \% \text {. } \\
\text { CNN applied for } \\
\text { classification }\end{array}$ \\
\hline
\end{tabular}




\begin{tabular}{|c|c|c|c|c|}
\hline Study & $\begin{array}{l}\text { Dataset } \\
\text { (Population) }\end{array}$ & Method & Measures & Findings \\
\hline Poplin et al. [133] & $\begin{array}{l}\mathrm{N}=48,101, \mathrm{~N}= \\
12,026 \text { Validation: } \\
\text { UK Biobank } \mathrm{N}= \\
236,234, \mathrm{~N}=999 \\
\text { EyePACS }\end{array}$ & $\begin{array}{l}\text { Inception-v3 neural } \\
\text { network } \\
\text { architecture. }\end{array}$ & $\begin{array}{l}\text { MAE in prediction. } \\
\text { AUC for the binary } \\
\text { classifier. Cohen's } \\
\text { kappa for multiclass } \\
\text { classification }\end{array}$ & $\begin{array}{l}\text { Age prediction: } \\
\text { MAE } 3.26 \text { years and } \\
3.48 \text { in UK Biobank } \\
\text { and EyePACS. } \\
\text { Ethnicity } \\
\text { prediction: Kappa } \\
\text { score of } 0.6 \text { and } \\
0.75 \text {. Prediction on } \\
\text { the onset of MACE: } \\
\text { AUC of } 0.7 \text { from } \\
\text { retinal fundus } \\
\text { images alone }\end{array}$ \\
\hline
\end{tabular}

MAE: Mean absolute error, MACE: Major adverse cardiac events

Bai et al. showed that Fully Convolution Network (FCN) matches expert like performance in speed, scalability and accuracy over CV magnetic resonant (CMR) image segmentation and clinical measurements [127]. In another study on fatty liver disease (FLD) tissue characterization, Kuppili et al. [131] observed accuracy of $96.75 \%$ using Symtosis ${ }^{\mathrm{TM}}$, an extreme learning machine (ELM). Further, Biswas et al. [130] developed a DL-based system and exhibited 100\% accuracy on a database of 63 samples. Meanwhile, Hemalatha et al. [132] used DL for analysing different grades of synovitis. The study observed an increase in false positives, a decrease in false negatives and an average accuracy of $95.02 \% \pm 2.78$ in 276 images. Wang et al. developed a CNN-based detection of calcification using mammograms and achieved human-like perfection [134]. Google used DL to analyse retinal fundus images and predicted multiple cardiovascular risk factors with good accuracy [133]. The team observed that retinal fundus images could accurately predict cardiovascular diseases and found method comparable to traditional risk calculators. Benchmarking studies and outcomes are summarized in Table III. Further, the favourable outcomes inspire the application of DL in stiffness computation.

\section{Stiffness computation using DL-framework and proposed work}

Stiffness measurements involve estimation of LD and IMT, state-of-the-art techniques applied in segmentation and analysis of lumen region are benchmarked in this section. Menchón-Lara et al. applied machine learning (ML) for carotid far-wall segmentation [120]. The method used multi-layer perceptron-based binary classifier to trace IMT and surmounted morphological variations in the artery. Segmentation error for LI, MA was $37.03 \pm 18.57 \mu \mathrm{m}, 34.52 \pm 10.29 \mu \mathrm{m}$ and IMT assessment error was $37.63 \pm 25.18 \mu \mathrm{m}$. Later, a modified algorithm by the same team applied DL-based classifier for ROI detection and was successful in almost all $(99.44 \pm 0.05 \%)$ cases [2]. The estimated mean IMT error reduced to $5.8 \pm 34 \mu \mathrm{m}$ for 67 subjects [2]. However, the study failed for near-wall analysis. Biswas et al. applied DL for lumen detection and characterisation [3]. The system used a 13-layered CNN for feature extraction (encoder), and a three-layered FCN for lumen segmentation (decoder); reported accuracy of $99.89 \%$ in LD measurement. Further, Jaccard index and Dice similarity for lumen segmentation on 407 images was 0.94 and 0.97 respectively and were effective in both far-wall and near-wall detection.

In a multi-frame approach, Tajbakhsh et al. automated frame selection, ROI localisation, and IMT measurement using DL [135]. Frames corresponding to the R wave in ECG were used as the reference in frame selection and carotid bulb ( $\sim 1 \mathrm{~cm}$ radius) was used for ROI localisation. This improved localisation error for LI but had little impact for MA due to low-contrast and poor gradient. Moreover, the results agreed with the expert readings ( $\mathrm{p}^{\sim} 0.5$ in ANOVA) on 44 videos from 11 subjects. Limited dataset affects the performance of DL-system so researchers used a patch-based approach. Lekadir et al. [136] used image patches on an 
architecture that included four CNN and three FCN layers for tissue characterization (as lipid core, fibrous and calcified). The authors applied 90,000 patches from readings of 56 subjects to train the network and were successful in $78.5 \%$ trials [136]. Perhaps, this was due to the limited dataset and quality of GT used to train the network. Studies on DL-based lumen segmentation techniques are compared in Table IV.

\section{Discussion}

From this, several conclusions can be derived. Important studies in stiffness assessment reported ambiguity caused by the non-uniformity in external distance measurement. Further, the external distance measurement does not consider the internal contour of the artery which is important. Researchers presented a difference in reference values of PWV owing to local or regional measurement. The image-based techniques propose an added advantage of presenting a clear idea of atherosclerosis. These techniques are either fully automated or semi, based on supervisor involvement. Moreover, these methods required arteries to be straight and horizontal for best performance. Further, noise and artefacts deteriorated the assessment. Evidence presented here is conclusive on the success of DL in lumen characterisation and segmentation. This paper proposes deep learning-based stiffness measurement from cine-loop, a short (ultrasound) video, of the carotid artery. Cineloop capture IMT and LD variations over many cardiac cycles and averaging over multiple frames diminish the effects of noise. Recently, Patel et al. [137] estimated elasticity using ELM. ELM was applied for ROI localisation, and in 100 images maximum-IMT and maximum-LD error were $20 \mathrm{~mm}$ and $91 \mathrm{~mm}$, respectively. However, the study estimated Young's modulus and at present little is known about the correlation between modulus of elasticity and cfPWV in a clinical setup.

The proposed method includes four stages of operation (illustration in Figure 4.): pre-processing, ROI localisation: extraction of lumen region, LD/IMT assessment and stiffness computation. The purpose of pre-processing is auto-crop of textual data with emphasis on tissue region. Pre-processing involves tasks such as brightness transformation, geometric transformation edge detection and image restoration in preparing the ultrasound image for the training and testing. Manual tracing by experts is used as GT for training. Networks for lumen and/or intima-adventitia are trained using separate GT. Further, down sampling is applied to improve processing efficiency. Often ECG recordings are made along with the carotid scan. Rwave is used to synchronize frames in consecutive cardiac cycles. IMT is processed from frames 5 seconds after R-wave to capture the extreme values during the two phases of the cardiac cycle: systole and diastole. Lumen region and IMC region are the ROI in stiffness computation leading to stiffness computation as analysed in Section 2 of this paper. ROI localisation is applied twice in the entire process: one for the identification of LI-far region and two for recognition of LI-near zone. LI-far facilitates the computation of IMT. Both LI-far and LI-near were required for the assessment of LD. LD/IMT assessment was performed using a poly-line distance method.

\section{Conclusion}

This study is important for several reasons. First, the review summarized trends in PWV assessment investigating leading research works. Further, arterial stiffness using image-based techniques were analyzed especially, localization, segmentation, and characterization. Besides, benchmarking DL-based work in medical framework inspired application in lumen segmentation and characterization. Finally, stiffness computation using DL is expected to work perfectly and provide reliable diagnostic support.

Table IV. Comparison of DL-based segmentation studies

\begin{tabular}{lllll}
\hline Study & Method & Dataset \& Size & Measures & Findings \\
\hline Menchón-Lara et al. & Multi-layer & $\mathrm{N}=60(30$ subjects $)$ & Bland-Altman plots, & Error in: LI \\
& perceptron binary & & mean absolute & $=37.03 \pm 18.57 \mu \mathrm{m}$, \\
& classifier & & distance, poly-line & $\mathrm{MA}=34.52 \pm 10.29$ \\
& & distance and & $\mu \mathrm{m}$, \\
& & centre-line distance. & $\mathrm{IMT}=37.63 \pm 25.18$ \\
& & & $\mu \mathrm{m}$
\end{tabular}




\begin{tabular}{|c|c|c|c|c|}
\hline Study & Method & Dataset \& Size & Measures & Findings \\
\hline $\begin{array}{l}\text { Menchón-Lara et al. } \\
{[2]}\end{array}$ & $\begin{array}{l}\text { ELM-based } \\
\text { autoencoder }\end{array}$ & $\mathrm{N}=67$ & $\begin{array}{l}\text { Mean absolute } \\
\text { difference, } \\
\text { correlation } \\
\text { coefficient }\end{array}$ & $\begin{array}{l}\text { Error in } \\
\mathrm{IMT}=5.79 \pm 34.42 \\
\mu \mathrm{m}\end{array}$ \\
\hline Biswas et al. [3] & $\begin{array}{l}\text { Encoder and } \\
\text { decoder based on } \\
\text { DL. }\end{array}$ & $\mathrm{N}=407(204)$ & $\begin{array}{l}\text { Precision-of-merit, } \\
\text { Figure-of-Merit } \\
\text { analysis, } \\
\text { inter-operator } \\
\text { variability, and } \\
\text { ROC analysis. }\end{array}$ & $\begin{array}{l}\text { LD measurement } \\
\text { accuracy }=99.89 \% \\
\text { Jaccard index and } \\
\text { Dice similarity for } \\
\text { lumen segmentation } \\
\text { on } 407 \text { images was } \\
0.94 \text { and } 0.97\end{array}$ \\
\hline $\begin{array}{l}\text { Tajbakhsh et al. } \\
\text { [135]. }\end{array}$ & $\begin{array}{l}\text { DL-based frame } \\
\text { selection, ROI } \\
\text { localisation, IMT } \\
\text { assessment }\end{array}$ & $\mathrm{N}=48$ videos $(12)$ & $\begin{array}{l}\text { Bland-Altman plot } \\
\text { Localisation error } \\
\text { FROC curve }\end{array}$ & $\begin{array}{l}\text { Error in LI }=2.68 \\
\mu \mathrm{m}, \mathrm{MA}=3.69 \mu \mathrm{m}, \\
\mathrm{IMT}=23.4 \pm 17.3 \\
\mu \mathrm{m} \text { Localisation } \\
\text { error }=0.19 \mathrm{~mm} \\
\text { (carotid bulb } \\
\text { region) and } 0.35 \\
\mathrm{~mm}\end{array}$ \\
\hline $\begin{array}{l}\text { Lekadir et al. } \\
{[136]}\end{array}$ & $\begin{array}{l}\text { CNN-based } \\
\text { plaque } \\
\text { characterization }\end{array}$ & $\begin{array}{l}\mathrm{N}=90000 \text { image } \\
\text { patches }(56)\end{array}$ & $\begin{array}{l}\text { Correlation }=0.90 \\
\text { with expert } \\
\text { readings. }\end{array}$ & $\begin{array}{l}78.5 \% \\
\text { improvement over } \\
\text { SVM method. } \\
\text { Real-time } \\
\text { processing. }\end{array}$ \\
\hline
\end{tabular}

Table V. Abbreviations and description

\begin{tabular}{ll}
\hline Abbreviations & Description \\
\hline AIx & Augmentation index \\
AS & Arterial stiffness \\
AUC & Area under the curve \\
baPWV & Branchial-ankle PWV \\
CAVI & Cardio-ankle vascular index \\
CCA & Common carotid artery \\
cfPWV & Carotid-femoral PWV \\
CNN & Convolutional neural network \\
CVD & Cardiovascular disease \\
D & Distensibility \\
DALY & Disability adjusted life lost \\
DBN & Deep belief network \\
DBN & Deep belief networks \\
DL & Deep learning \\
ELM & Extreme learning machine \\
FCN & Fully convolutional neural network \\
FoM & Figure of merit \\
FVE & Fourier velocity encoder \\
GT & Ground truth \\
IMC & Intima-media complex \\
IMT & Intima-media thickness
\end{tabular}




\begin{tabular}{ll}
\hline Abbreviations & Description \\
\hline LD & Lumen diameter \\
MA & Media-adventitia \\
MACE & Major adverse cardiac events \\
MRI & Magnetic resonance imaging \\
PoM & Precision of merit \\
PP & Pulse pressure \\
PWV & Pulse wave velocity \\
RBM & Restricted Boltzmann machine \\
RBM & Restricted Boltzmann machine \\
RMSE & Root mean square error \\
RNN & Recurrent neural network \\
ROC & Region of convergence \\
ROI & Region of interest \\
SSI & Stenosis severity index \\
SVM & Support vector machine \\
YLL & Years of life lost \\
\hline
\end{tabular}

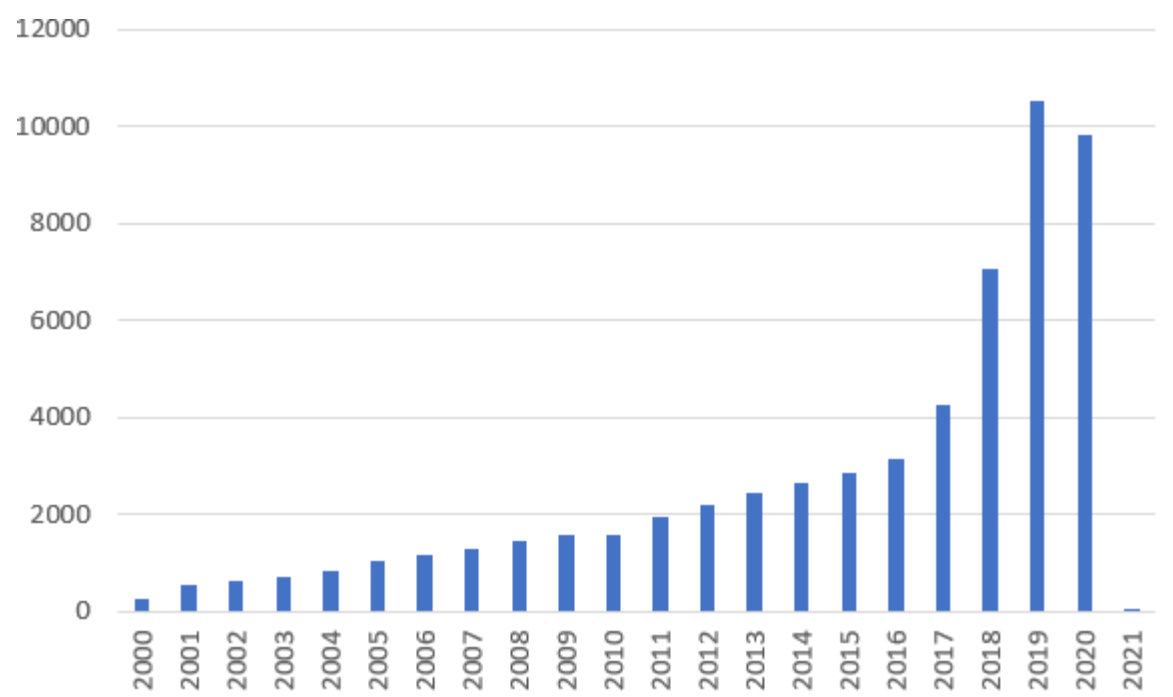

Figure 1. Chart on count of articles from 2000 to 2021 for arterial stiffness 


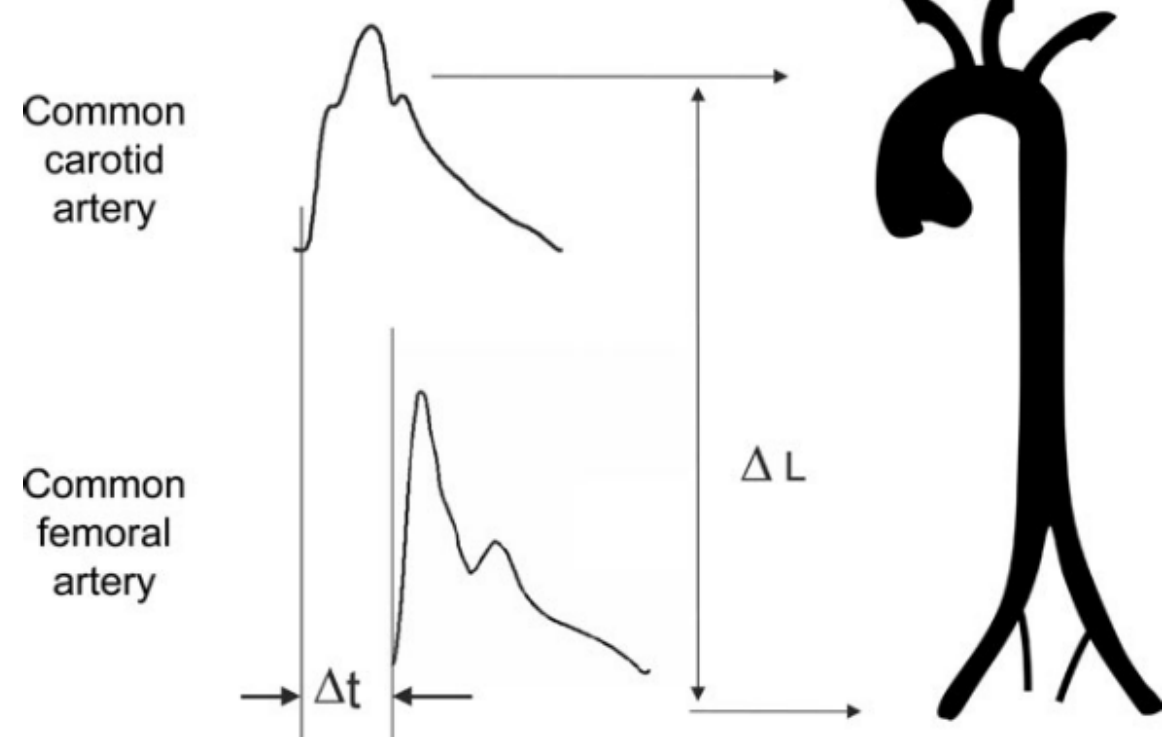

Figure 2. Two-site method for evaluation of PWV (cfPWV) (courtesy Lorent et al.[46])

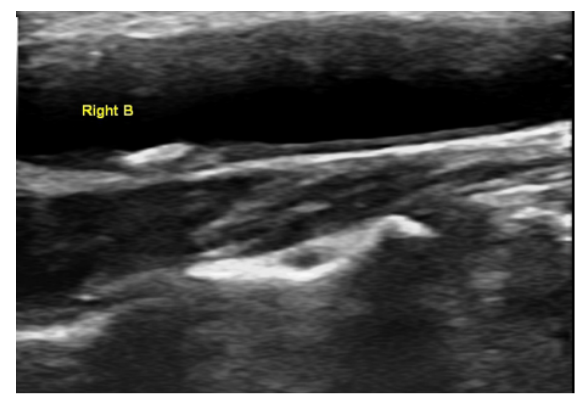

(a)

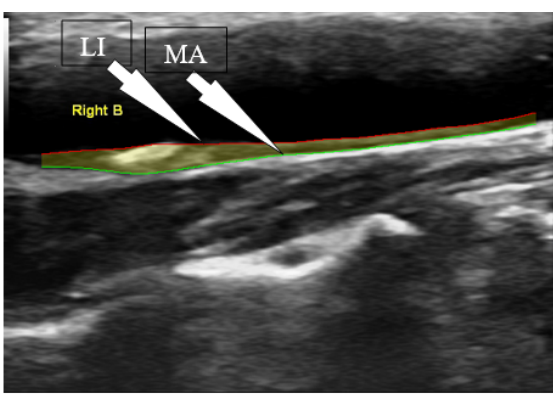

(b)

Figure 3. Longitudinal section of the common carotid artery. (a) original image (b) here LI and MA borders are delineated.

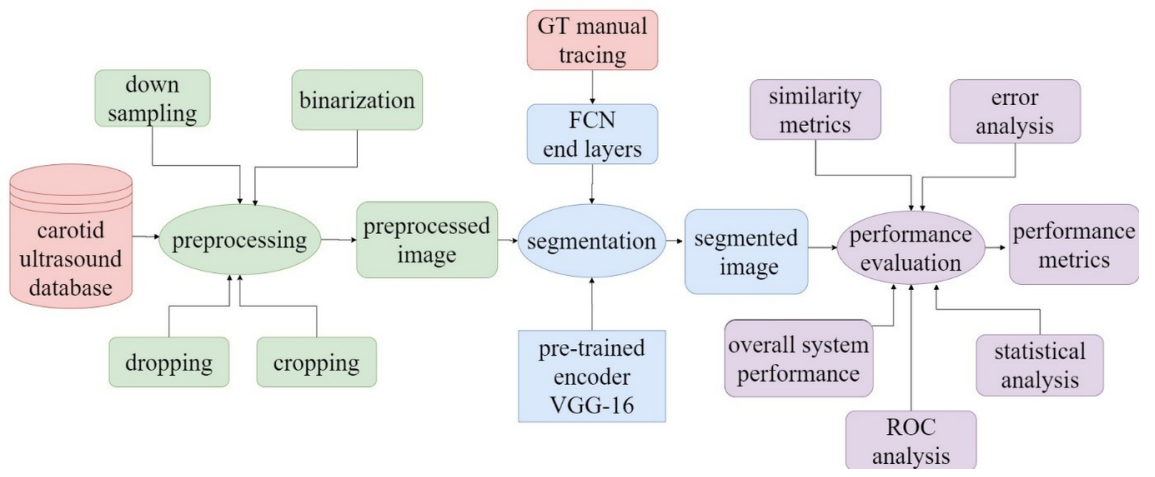

Figure 4. DL architecture for lumen segmentation 


\section{Appendix A}

\section{Stiffness indices}

Compliance coefficient of a vessel wall is defined as [138]C $=\underline{\Delta \mathrm{A}}$

greekp $=\left[\pi D_{d}\left(D_{s}-D_{d}\right) / 2\right] / \Delta \Pi$ where $\Delta \mathrm{A}$ is change in cross-sectional area; $\Delta \Pi$ is pulse pressure; $D_{s}, D_{d}$ are arterial diameter in systole and diastole respectively. The distensibility coefficient is described as [138]:

$D=\underline{\Delta \mathrm{A}}$

greekA . $\mathrm{p}=2\left[\left(D_{s}-D_{d}\right) / D_{d}\right] \Delta \Pi$

Pulse wave velocity (PWV) as explained by Bramwell and Hill is [138]:

$$
\mathrm{PWV}=\sqrt{\frac{\Delta \Pi}{\rho \cdot \Delta^{\prime}}}=\frac{1}{\sqrt{\rho \cdot \Delta}}=\sqrt{\frac{D_{d}^{2} \Delta \Pi}{\rho\left(2 \cdot D_{d} \cdot \Delta D+\Delta D^{2}\right)}}
$$

A significant version applied for the analysis of PWV is using the Moens-Korteweg equation:

$$
\mathrm{PWV}=\sqrt{\frac{\mathrm{E} \cdot \mathrm{h}}{2 \cdot r \cdot \rho}}
$$

where $\Delta D$ is the alteration in artery diameter, $\rho$ is the density of blood. $\mathrm{E}$ is the young's modulus, $\mathrm{h}$ is the IMT and $r$ is the radius of the artery. The stiffness-index $\beta$ is stated as [139]:

$$
\beta=\underline{\Delta \Pi}
$$

$\operatorname{english}\left(D_{s}-D_{d}\right) / D_{d}$

Augmentation index is the difference between first and second systolic peaks in pressure waveform relative to PP. AIx is analysed from pressure waveform and is stated as [139]:

$$
\begin{gathered}
\mathrm{AIx}=\frac{\left(P_{1}-P_{2}\right)}{\mathrm{PP}} \cdot 100 \% \\
\beta=\frac{\ln \left(P_{s} / P_{d}\right)}{\left(D_{s}-D_{d}\right) / D_{d}}
\end{gathered}
$$

Cardio-ankle vascular index (CAVI) is an indicator of stiffness from the aorta to ankle [140]. CAVI is defined as:

$$
\mathrm{CAVI}=a\left[\frac{2 \rho}{\Delta \Pi} \ln \left(P_{s} / P_{d}\right) \cdot \mathrm{PW} V^{2}\right]+b
$$

where $a$ and $b$ are adjustable constants.

\section{References}

[1] S. Sudha, K.B. Jayanthi, C. Rajasekaran, N. Madian, T. Sunder, Convolutional Neural Network for Segmentation and Measurement of Intima Media Thickness, J. Med. Syst. 42 (2018). https://doi.org/10.1007/s10916-018-1001-y. 
[2] R.-M. Menchón-Lara, J.-L. Sancho-Gómez, A. Bueno-Crespo, Early-stage atherosclerosis detection using deep learning over carotid ultrasound images, Appl. Soft Comput. 49 (2016) 616-628. https://doi.org/10.1016/j.asoc.2016.08.055.

[3] M. Biswas, V. Kuppili, L. Saba, D.R. Edla, H.S. Suri, A. Sharma, E. Cuadrado-Godia, J.R. Laird, A. Nicolaides, J.S. Suri, Deep learning fully convolution network for lumen characterization in diabetic patients using carotid ultrasound: a tool for stroke risk, Med. Biol. Eng. Comput. 57 (2019) 543-564. https://doi.org/10.1007/s11517-018-1897-x.

[4] World Health Organisation, The Top 10 Causes of Death, (n.d.). https://www.who.int/news-room/factsheets/detail/the-top-10-causes-of-death.

[5] G.A. Roth, C. Johnson, A. Abajobir, F. Abd-Allah, S.F. Abera, G. Abyu, M. Ahmed, B. Aksut, T. Alam, K. Alam, others, Global, regional, and national burden of cardiovascular diseases for 10 causes, 1990 to 2015, J. Am. Coll. Cardiol. 70 (2017) 1-25.

[6] P. Bovet, F. Paccaud, Cardiovascular Disease and the Changing Face of Global Public Health: A Focus on Low and Middle Income Countries, Public Health Rev. 33 (2011) 397-415. https://doi.org/10.1007/bf03391643.

[7] A. Alwan, D.R. MacLean, A review of non-communicable disease in low- and middle-income countries, Int. Health. 1 (2009) 3-9. https://doi.org/10.1016/j.inhe.2009.02.003.

[8] Y.J. Yasin, J.A.M. Banoub, A. Husseini, GBD 2017 Causes of Death Collaborators. Global, regional, and national age-sex-specific mortality for 282 causes of death in 195 countries and territories, 1980-2017: a systematic analysis for the Global Burden of Disease Study 2017 (vol 392, pg 1736, 201, Lancet. 393 (2019) E44-E44.

[9] N.J. Kassebaum, M. Arora, R.M. Barber, Z.A. Bhutta, J. Brown, A. Carter, D.C. Casey, F.J. Charlson, M.M. Coates, M. Coggeshall, others, Global, regional, and national disability-adjusted life-years (DALYs) for 315 diseases and injuries and healthy life expectancy (HALE), 1990-2015: a systematic analysis for the Global Burden of Disease Study 2015, Lancet. 388 (2016) 1603-1658.

[10] A.C. Carlsson, B. Starrin, B. Gigante, K. Leander, M.L. Hellenius, U. De Faire, Financial stress in late adulthood and diverse risks of incident cardiovascular disease and all-cause mortality in women and men, BMC Public Health. 14 (2014) 17. https://doi.org/10.1186/1471-2458-14-17.

[11] A. Georgiades, I. Janszky, M. Blom, K.D. László, S. Ahnve, Financial strain predicts recurrent events among women with coronary artery disease, Int. J. Cardiol. 135 (2009) 175-183. https://doi.org/10.1016/j.ijcard.2008.03.093.

[12] V. Viswanathan, A.D. Jamthikar, D. Gupta, N. Shanu, A. Puvvula, N.N. Khanna, L. Saba, T. Omerzum, K. Viskovic, S. Mavrogeni, M. Turk, J.R. Laird, G. Pareek, M. Miner, P.P. Sfikakis, A. Protogerou, G.D. Kitas, C. S, S. Joshi, H. Fiscian, A.A. Folson, D.H. Wu, Z. Ruzsa, A. Nicolaides, A. Sharma, D.L. Bhatt, J.S. Suri, Low-cost preventive screening using carotid ultrasound in patients with diabetes., Front. Biosci. (Landmark Ed. 25 (2020) 1132-1171. http://www.ncbi.nlm.nih.gov/pubmed/32114427 (accessed April 13, 2020).

[13] A. Gheorghe, U. Griffiths, A. Murphy, H. Legido-quigley, P. Lamptey, P. Perel, The economic burden of cardiovascular disease and hypertension in low- and middle-income countries : a systematic review, (2018) $1-11$.

[14] A.J. Lusis, Atherosclerosis, Nature. 407 (2000) 233-241. https://doi.org/10.1038/35025203.

[15] Y. Sherer, Y. Shoenfeld, Mechanisms of Disease: atherosclerosis in autoimmune diseases, Nat. Clin. Pract. Rheumatol. 2 (2006) 99-106. https://doi.org/10.1038/ncprheum0092.

[16] R. Ross, Atherosclerosis-An Inflammatory Disease, NEJM. 340 (1999) 12. 
[17] A.L. Wentland, T.M. Grist, O. Wieben, Review of MRI-based measurements of pulse wave velocity: a biomarker of arterial stiffness., Cardiovasc. Diagn. Ther. 4 (2014) 193-206. https://doi.org/10.3978/j.issn.2223-3652.2014.03.04.

[18] P.H. Davis, J.D. Dawson, W.A. Riley, R.M. Lauer, Carotid intimal-medial thickness is related to cardiovascular risk factors measured from childhood through middle age the muscatine Study, Circulation. 104 (2001) 2815-2819. https://doi.org/10.1161/hc4601.099486.

[19] J.D. Savant, S.L. Furth, K.E.C. Meyers, Arterial Stiffness in Children: Pediatric Measurement and Considerations, Pulse. 2 (2015) 69-80. https://doi.org/10.1159/000374095.

[20] A.E. Schutte, R. Kruger, L.F. Gafane-Matemane, Y. Breet, M. Strauss-Kruger, J.K. Cruickshank, Ethnicity and Arterial Stiffness, Arterioscler. Thromb. Vasc. Biol. (2020) ATVBAHA120313133. https://doi.org/10.1161/ATVBAHA.120.313133.

[21] F.U.S. Mattace-Raso, T.J.M. Van Der Cammen, A. Hofman, N.M. Van Popele, M.L. Bos, M.A.D.H. Schalekamp, R. Asmar, R.S. Reneman, A.P.G. Hoeks, M.M.B. Breteler, J.C.M. Witteman, Arterial stiffness and risk of coronary heart disease and stroke: The Rotterdam Study, Circulation. 113 (2006) 657-663. https://doi.org/10.1161/CIRCULATIONAHA.105.555235.

[22] G.F. Mitchell, S.J. Hwang, R.S. Vasan, M.G. Larson, M.J. Pencina, N.M. Hamburg, J.A. Vita, D. Levy, E.J. Benjamin, Arterial stiffness and cardiovascular events: The framingham heart study, Circulation. 121 (2010) 505-511. https://doi.org/10.1161/CIRCULATIONAHA.109.886655.

[23] Y. Chen, F. Shen, J. Liu, G.Y. Yang, Arterial stiffness and stroke: De-stiffening strategy, a therapeutic target for stroke, Stroke Vasc. Neurol. 2 (2017) 65-72. https://doi.org/10.1136/svn-2016-000045.

[24] A.D. Gepner, C.E. Korcarz, L.A. Colangelo, E.K. Hom, M.C. Tattersall, B.C. Astor, J.D. Kaufman, K. Liu, J.H. Stein, Longitudinal effects of a decade of aging on carotid artery stiffness : The multiethnic study of atherosclerosis, Stroke. 45 (2014) 48-53. https://doi.org/10.1161/STROKEAHA.113.002649.

[25] P. V Vaitkevicius, J.L. Fleg, J.H. Engel, F.C. O'Connor, J.G. Wright, L.E. Lakatta, F.C. Yin, E.G. Lakatta, Effects of age and aerobic capacity on arterial stiffness in healthy adults., Circulation. 88 (1993) 1456-1462. https://doi.org/10.1161/01.CIR.88.4.1456.

[26] A. Benetos, S. Laurent, A.P. Hoeks, P.H. Boutouyrie, M.E. Safar, Arterial alterations with aging and high blood pressure, (Arteriosclerosis Thromb. 13 (1993) 90-97.

[27] A. Benetos, B. Waeber, J. Izzo, G.Mitchell, L. Resnick, R. Asmar, Influence of age, risk factors, and cardiovascular and renal disease on arterial stiffness: Clinical applications, Am. J. Hypertens. $15 \quad(2002)$ 1101-1108. http://ovidsp.ovid.com/ovidweb.cgi?T=JS\&PAGE=reference\&D=emed8\&NEWS=N\&AN=35397546.

[28] E. Oikonomou, G. Vogiatzi, G. Lazaros, S. Tsalamandris, A. Goliopoulou, V. Mystakidou, P. Theofilis, E. Christoforatou, C. Chasikidis, D. Tousoulis, Relationship of depressive symptoms with arterial stiffness and carotid atherosclerotic burden in the Corinthia study, QJM An Int. J. Med. (2020). https://doi.org/10.1093/qjmed/hcaa079.

[29] D. Liao, D.K. Arnett, H.A. Tyroler, W.A. Riley, L.E. Chambless, M. Szklo, G. Heiss, Arterial Stiffness and the Development of Hypertension, Hypertension. 34 (1999) 201-206. https://doi.org/10.1161/01.HYP.34.2.201.

[30] J. Dernellis, M. Panaretou, Aortic stiffness is an independent predictor of progression to hypertension in nonhypertensive subjects, Hypertension. 45 (2005) 426-431. https://doi.org/10.1161/01.HYP.0000157818.58878.93.

[31] H. Takase, Y. Dohi, T. Toriyama, T. Okado, S. Tanaka, H. Sonoda, K. Sato, G. Kimura, Brachial-ankle pulse wave velocity predicts increase in blood pressure and onset of hypertension, Am. J. Hypertens. 24 
(2011) 667-673. https://doi.org/10.1038/ajh.2011.19.

[32] S.S. Najjar, A. Scuteri, V. Shetty, J.G. Wright, D.C. Muller, J.L. Fleg, H.P. Spurgeon, L. Ferrucci, E.G. Lakatta, Pulse Wave Velocity Is an Independent Predictor of the Longitudinal Increase in Systolic Blood Pressure and of Incident Hypertension in the Baltimore Longitudinal Study of Aging, J. Am. Coll. Cardiol. 51 (2008) 1377-1383. https://doi.org/10.1016/j.jacc.2007.10.065.

[33] M. Yambe, H. Tomiyama, Y. Hirayama, Z. Gulniza, Y. Takata, Y. Koji, K. Motobe, A. Yamashina, Arterial Stiffening as a Possible Risk Factor for Both Atherosclerosis and Diastolic Heart Failure, n.d. https://www.jstage.jst.go.jp/article/hypres/27/9/27_9_625/_article/-char/ja/ (accessed March 28, 2020).

[34] G.F. Mitchell, S.-J. Hwang, R.S. Vasan, M.G. Larson, M.J. Pencina, N.M. Hamburg, J.A. Vita, D. Levy, E.J. Benjamin, Arterial Stiffness and Cardiovascular Events. The Framingham Heart Study, Circulation. 121 (2010) 505-511. https://doi.org/10.1161/CIRCULATIONAHA.109.886655.

[35] J. Kim, M.J. Cha, D.H. Lee, H.S. Lee, C.M. Nam, H.S. Nam, Y.D. Kim, J.H. Heo, The association between cerebral atherosclerosis and arterial stiffness in acute ischemic stroke, Atherosclerosis. 219 (2011) 887-891. https://doi.org/10.1016/j.atherosclerosis.2011.09.013.

[36] T. Pereira, J. Maldonado, L. Pereira, J. Conde, Aortic Stiffness is an Independent Predictor of Stroke in Hypertensive Patients, Arq. Bras. Cardiol. 258 (2013) 1236-1241. https://doi.org/10.5935/abc.20130079.

[37] S.B. Prenner, J.A. Chirinos, Arterial stiffness in diabetes mellitus, Atherosclerosis. 238 (2015) 370-379. https://doi.org/10.1016/j.atherosclerosis.2014.12.023.

[38] E. Sciatti, E. Vizzardi, A. Castiello, F. Valentini, I. Bonadei, S. Gelsomino, R. Lorusso, M. Metra, The role of type 2 diabetes mellitus on hypertensive-related aortic stiffness, Echocardiography. 35 (2018) 798-803. https://doi.org/10.1111/echo.13841.

[39] G.S. Berenson, S.R. Srinivasan, Emergence of obesity and cardiovascular risk for coronary artery disease: the Bogalusa Heart Study., Prev. Cardiol. 4 (2001) 116-121. http://www.embase.com/search/results?subaction=viewrecord\&from=export\&id=L32613803.

[40] K. Sutton-Tyrrell, A. Newman, E.M. Simonsick, R. Havlik, M. Pahor, E. Lakatta, H. Spurgeon, P. Vaitkevicius, Aortic stiffness is associated with visceral adiposity in older adults enrolled in the Study of Health, Aging, and Body Composition, Hypertension. 38 (2001) 429-433. https://doi.org/10.1161/01.HYP.38.3.429.

[41] R.P. Wildman, R.H. Mackey, A. Bostom, T. Thompson, K. Sutton-Tyrrell, Measures of obesity are associated with vascular stiffness in young and older adults, Hypertension. 42 (2003) 468-473. https://doi.org/10.1161/01.HYP.0000090360.78539.CD.

[42] M. Kanbay, B. Afsar, P. Gusbeth-Tatomir, A. Covic, Arterial stiffness in dialysis patients: Where are we now?, Int. Urol. Nephrol. 42 (2010) 741-752. https://doi.org/10.1007/s11255-009-9675-1.

[43] R.R. Townsend, A.H. Anderson, J.A. Chirinos, H.I. Feldman, J.E. Grunwald, L. Nessel, J. Roy, M.R. Weir, J.T. Wright, N. Bansal, C.Y. Hsu, J.W. Kusek, M. Rahman, Association of pulse wave velocity with chronic kidney disease progression and mortality findings from the CRIC Study (Chronic Renal Insufficiency Cohort), Hypertension. 71 (2018) 1101-1107. https://doi.org/10.1161/HYPERTENSIONAHA.117.10648.

[44] M. O'Rourke, C. Hartley, D. McDonald, McDonald's blood flow in arteries: theoretic, experimental, and clinical principles, (1998).

[45] J.J. Oliver, D.J. Webb, Noninvasive assessment of arterial stiffness and risk of atherosclerotic events, Arterioscler. Thromb. Vasc. Biol. 23 (2003) 554-566. https://doi.org/10.1161/01.ATV.0000060460.52916.D6.

[46] S. Laurent, J. Cockcroft, L. Van Bortel, P. Boutouyrie, C. Giannattasio, D. Hayoz, B. Pannier, C. Vlachopoulos, I. Wilkinson, H. Struijker-Boudier, Expert consensus document on arterial stiffness: Methodological issues and clinical applications, Eur. Heart J. 27 (2006) 2588-2605. https://doi.org/10.1093/eurheartj/ehl254. 
[47] P. Hallock, I.C. Benson, STUDIES ON THE ELASTIC PROPERTIES OF HUMAN ISOLATED AORTA, J. Clin. Invest. 16 (1937) 595-602. https://doi.org/10.1172/JCI100886.

[48] P. Hallock, I.C. Benson, STUDIES ON THE ELASTIC PROPERTIES OF HUMAN ISOLATED AORTA, J. Clin. Invest. 16 (1937) 595-602. https://doi.org/10.1172/jci100886.

[49] M. Gevers, W.W. Hack, E.F. Ree, H.N. Lafeber, N. Westerhof, Arterial blood pressure wave forms in radial and posterior tibial arteries in critically ill newborn infants., J. Dev. Physiol. 19 (1993) 179-85. http://www.ncbi.nlm.nih.gov/pubmed/8089447 (accessed April 19, 2020).

[50] C.S. Uiterwaal, S. Anthony, L.J. Launer, J.C. Witteman, A.M. Trouwborst, A. Hofman, D.E. Grobbee, Birth weight, growth, and blood pressure: an annual follow-up study of children aged 5 through 21 years., Hypertens. (Dallas, Tex. 1979). 30 (1997) 267-71. https://doi.org/10.1161/01.hyp.30.2.267.

[51] G.F. Mitchell, H. Parise, E.J. Benjamin, M.G. Larson, M.J. Keyes, J.A. Vita, R.S. Vasan, D. Levy, Changes in arterial stiffness and wave reflection with advancing age in healthy men and women: The Framingham Heart Study, Hypertension. 43 (2004) 1239-1245. https://doi.org/10.1161/01.HYP.0000128420.01881.aa.

[52] R. Kelly, C. Hayward, A. Avolio, M. O'Rourke, Noninvasive determination of age-related changes in the human arterial pulse., Circulation. 80 (1989) 1652-1659. https://doi.org/10.1161/01.CIR.80.6.1652.

[53] K.L. Jablonski, A.J. Donato, B.S. Fleenor, M.J. Nowlan, A.E. Walker, R.E. Kaplon, D.B. Ballak, D.R. Seals, Reduced large elastic artery stiffness with regular aerobic exercise inmiddle-agedandolder adults: Potential role of suppressed nuclear factor $\chi$ B signalling, J. Hypertens. 33 (2015) 2477-2482. https://doi.org/10.1097/HJH.0000000000000742.

[54] N. Fujimoto, A. Prasad, J.L. Hastings, A. Arbab-Zadeh, P.S. Bhella, S. Shibata, D. Palmer, B.D. Levine, Cardiovascular effects of 1 year of progressive and vigorous exercise training in previously sedentary individuals older than 65 years of age, Circulation. 122 (2010) 1797-1805. https://doi.org/10.1161/CIRCULATIONAHA.110.973784.

[55] J. Westerbacka, I. Wilkinson, J. Cockcroft, T. Utriainen, S. Vehkavaara, H. Yki-Järvinen, Diminished wave reflection in the aorta: A novel physiological action of insulin on large blood vessels, Hypertension. 33 (1999) 1118-1122. https://doi.org/10.1161/01.HYP.33.5.1118.

[56] M. Tamminen, J. Westerbacka, S. Vehkavaara, H. Yki-Järvinen, Insulin-induced decreases in aortic wave reflection and central systolic pressure are impaired in type 2 diabetes., Diabetes Care. 25 (2002) 2314-2319. https://doi.org/10.2337/diacare.25.12.2314.

[57] M.F.O. Rourke, A. Pauca, X. Jiang, Pulse wave analysis, (2001) 507-522.

[58] G.M. London, A.P. Guerin, B. Pannier, S.J. Marchais, M. Stimpel, Influence of sex on arterial hemodynamics and blood pressure: Role of body height, in: Hypertension, Lippincott Williams and Wilkins, 1995: pp. 514-519. https://doi.org/10.1161/01.HYP.26.3.514.

[59] C.S. Hayward, R.P. Kelly, Gender-related differences in the central arterial pressure waveform, J. Am. Coll. Cardiol. 30 (1997) 1863-1871. https://doi.org/10.1016/S0735-1097(97)00378-1.

[60] Y. Zhang, P. Lacolley, A.D. Protogerou, M.E. Safar, Arterial Stiffness in Hypertension and Function of Large Arteries, Am. J. Hypertens. 33 (2020) 291-296. https://doi.org/10.1093/ajh/hpz193.

[61] B.A. Brooks, L.M. Molyneaux, D.K. Yue, Augmentation of central arterial pressure in type 2 diabetes, Diabet. Med. 18 (2001) 374-380. https://doi.org/10.1046/j.1464-5491.2001.00479.x.

[62] B. Brooks, L. Molyneaux, D.K. Yue, Augmentation of central arterial pressure in type 1 diabetes, Diabetes Care. 22 (1999) 1722-1727. https://doi.org/10.2337/diacare.22.10.1722. 
[63] K. Takagi, S. Ishihara, N. Kenji, H. Iha, N. Kobayashi, Y. Ito, T. Nohara, S. Ohkuma, T. Mitsuishi, A. Ishizuka, S. Shigihara, M. Sone, H. Tokuyama, T. Omote, A. Kikuchi, S. Nakamura, E. Yamamoto, M. Ishikawa, K. Amitani, N. Takahashi, Y. Maruyama, H. Imura, N. Sato, W. Shimizu, Clinical significance of arterial stiffness as a factor for hospitalization of heart failure with preserved left ventricular ejection fraction: a retrospective matched case-control study, J. Cardiol. (2020). https://doi.org/10.1016/j.jjcc.2020.02.013.

[64] B. Gavish, J.L. Izzo, Arterial Stiffness: Going a Step beyond, Am. J. Hypertens. 29 (2016) 1223-1233. https://doi.org/10.1093/ajh/hpw061.

[65] H. Tanaka, M. Munakata, Y. Kawano, M. Ohishi, T. Shoji, J. Sugawara, H. Tomiyama, A. Yamashina, H. Yasuda, T. Sawayama, T. Ozawa, Comparison between carotid-femoral and brachialankle pulse wave velocity as measures of arterial stiffness, J. Hypertens. 27 (2009) 2022-2027. https://doi.org/10.1097/HJH.0b013e32832e94e7.

[66] R.R. Townsend, I.B. Wilkinson, E.L. Schiffrin, A.P. Avolio, J.A. Chirinos, J.R. Cockcroft, K.S. Heffernan, E.G. Lakatta, C.M. McEniery, G.F. Mitchell, S.S. Najjar, W.W. Nichols, E.M. Urbina, T. Weber, Recommendations for Improving and Standardizing Vascular Research on Arterial Stiffness, 2015. https://doi.org/10.1161/hyp.0000000000000033.

[67] L.M. Van Bortel, S. Laurent, P. Boutouyrie, P. Chowienczyk, J.K. Cruickshank, T. De Backer, J. Filipovsky, S. Huybrechts, F.U.S. Mattace-Raso, A.D. Protogerou, G. Schillaci, P. Segers, S. Vermeersch, T. Weber, Expert consensus document on the measurement of aortic stiffness in daily practice using carotid-femoral pulse wave velocity, J. Hypertens. 30 (2012) 445-448. https://doi.org/10.1097/HJH.0b013e32834fa8b0.

[68] S.J. Al Aref, K. Anchouche, G. Singh, P.J. Slomka, K.K. Kolli, A. Kumar, M. Pandey, G. Maliakal, A.R. Van Rosendael, A.N. Beecy, D.S. Berman, J. Leipsic, K. Nieman, D. Andreini, G. Pontone, U.J. Schoepf, L.J. Shaw, H. Chang, J. Narula, J.J. Bax, Y. Guan, J.K. Min, Clinical applications of machine learning in cardiovascular disease and its relevance to cardiac imaging, (2018) 1-14. https://doi.org/10.1093/eurheartj/ehy404.

[69] Y. LeCun, Y. Bengio, G. Hinton, Deep learning, Nature. 521 (2015) 436-444. https://doi.org/10.1038/nature14539.

[70] I. Goodfellow, Deep Learning, (n.d.).

[71] Y. Bengio, P. Lamblin, D. Popovici, H. Larochelle, Greedy layer-wise training of deep networks, Adv. Neural Inf. Process. Syst. (2007) 153-160.

[72] P. Vincent, H. Larochelle, Extracting and Composing Robust Features with Denoising.pdf, (2008) 10961103.

[73] A. Redheuil, W. Yu, C.O. Wu, E. Mousseaux, A. De Cesare, R. Yan, N. Kachenoura, D. Bluemke, J.A.C. Lima, Reduced Ascending Aortic Strain and Distensibility Earliest Manifestations of Vascular Aging in Humans, (2010). https://doi.org/10.1161/HYPERTENSIONAHA.109.141275.

[74] M.E. Safar, R. Asmar, A. Benetos, J. Blacher, P. Boutouyrie, P. Lacolley, S. Laurent, G. London, B. Pannier, A. Protogerou, Interaction Between Hypertension and Arterial Stiffness, Hypertens. (Dallas, Tex. 1979). 72 (2018) 796-805. https://doi.org/10.1161/HYPERTENSIONAHA.118.11212.

[75] H. Obeid, V. Ouedraogo, M. Hallab, Arterial Stiffness: A New Biomarker to be Measured, J. Arch. Mil. Med. 5 (2017). https://doi.org/10.5812/jamm.47078.

[76] S. Laurent, J. Cockcroft, L. Van Bortel, P. Boutouyrie, C. Giannattasio, D. Hayoz, B. Pannier, C. Vlachopoulos, I. Wilkinson, H. Struijker-Boudier, Expert consensus document on arterial stiffness: methodological issues and clinical applications, Eur. Heart J. 27 (2006) 2588-2605. https://doi.org/10.1093/eurheartj/ehl254.

[77] F.J. Callaghan, L.A. Geddes, C.F. Babbs, J.D. Bourland, Relationship between pulse-wave velocity and arterial elasticity, Med. Biol. Eng. Comput. 24 (1986) 248-254. https://doi.org/10.1007/BF02441620. 
[78] K. Shirai, J. Utino, K. Otsuka, M. Takata, A novel blood pressure-independent arterial wall stiffness parameter, J. Atheroscler. Thromb. 13 (2006) 101-107. http://link.kesli.or.kr:3210/cmclib?sid=Entrez:PubMed.

[79] S. Vulliémoz, N. Stergiopulos, R. Meuli, Estimation of local aortic elastic properties with MRI, Magn. Reson. Med. 47 (2002) 649-654. https://doi.org/10.1002/mrm.10100.

[80] S.W. Fielden, B.K. Fornwalt, M. Jerosch-Herold, R.L. Eisner, A.E. Stillman, J.N. Oshinski, A new method for the determination of aortic pulse wave velocity using cross-correlation on 2D PCMR velocity data, J. Magn. Reson. Imaging. 27 (2008) 1382-1387. https://doi.org/10.1002/jmri.21387.

[81] N. Jatoi, A. Mahmud, K. Bennett, J.F.-J. of hypertension, undefined 2009, Assessment of arterial stiffness in hypertension: comparison of oscillometric (Arteriograph), piezoelectronic (Complior) and tonometric (SphygmoCor) techniques, Journals.Lww.Com. (n.d.). https://journals.lww.com/jhypertension/Fulltext/2009/11000/Tranilast_attenuates_myocardial_fibrosis_in.6.aspx (accessed July 25, 2020).

[82] M. Butlin, A. Qasem, Large Artery Stiffness Assessment Using SphygmoCor Technology, Pulse. 4 (2016) 180-192. https://doi.org/10.1159/000452448.

[83] S.S. Hickson, M. Butlin, J. Broad, A.P. Avolio, I.B. Wilkinson, C.M. McEniery, Validity and repeatability of the Vicorder apparatus: A comparison with the SphygmoCor device, Hypertens. Res. 32 (2009) 1079-1085. https://doi.org/10.1038/hr.2009.154.

[84] P. Salvi, G. Lio, C. Labat, E. Ricci, ... B.P.-J. of, undefined 2004, Validation of a new non-invasive portable tonometer for determining arterial pressure wave and pulse wave velocity: the PulsePen device, Journals.Lww.Com. (n.d.). https://journals.lww.com/jhypertension/fulltext/2004/12000/validation_of_a_new_non_invasive_portable.10.aspx (accessed July 25, 2020).

[85] J.L. Taylor, T.B. Curry, L.J. Matzek, M.J. Joyner, D.P. Casey, Acute Effects of a Mixed Meal on Arterial Stiffness and Central Hemodynamics in Healthy Adults, Am. J. Hypertens. 27 (2014) 331. https://doi.org/10.1093/ajh/hpt211.

[86] A. Mahmud, J. Feely, Acute Effect of Caffeine on Arterial Stiffness and Aortic Pressure Waveform, Hypertension. 38 (2001) 227-231. https://doi.org/10.1161/01.HYP.38.2.227.

[87] A. Mahmud, J. Feely, Effect of smoking on arterial stiffness and pulse pressure amplification, Hypertension. 41 (2003) 183-187. https://doi.org/10.1161/01.HYP.0000047464.66901.60.

[88] T. Araki, A.M. Kumar, P.K. Kumar, A. Gupta, L. Saba, J. Rajan, F. Lavra, A.M. Sharma, S. Shafique, A. Nicolaides, J.R. Laird, J.S. Suri, Ultrasound-based automated carotid lumen diameter/stenosis measurement and its validation system, J. Vasc. Ultrasound. 40 (2016) 120-134. https://doi.org/10.1177/154431671604000302.

[89] J.R.H. Kumar, K. Teotia, P.K. Raj, J. Andrade, K. V Rajagopal, C.S. Seelamantula, AUTOMATIC SEGMENTATION OF COMMON CAROTID ARTERY IN LONGITUDINAL MODE ULTRASOUND IMAGES USING ACTIVE OBLONGS Department of Electrical Engineering, Indian Institute of Science, Bangalore , India Department of Electrical and Electronics Engineering, Manip, (2019) 1353-1357.

[90] S. Petroudi, C. Loizou, M. Pantziaris, C. Pattichis, Segmentation of the common carotid intima-media complex in ultrasound images using active contours, IEEE Trans. Biomed. Eng. 59 (2012) 3060-3069. https://doi.org/10.1109/TBME.2012.2214387.

[91] A.M.F. Santos, J.M.R.S. Tavares, L. Sousa, R. Santos, P. Castro, E. Azevedo, Automatic segmentation of the lumen of the carotid artery in ultrasound B-mode images, Med. Imaging 2013 Comput. Diagnosis. 8670 (2013) 86703I. https://doi.org/10.1117/12.2007259.

[92] A.M.F. Santos, J.M.R.S. Tavares, L. Sousa, R. Santos, P. Castro, E. Azevedo, Automatic segmentation of the lumen of the carotid artery in ultrasound B-mode images, in: C.L. Novak, S. Aylward (Eds.), Med. 
Imaging 2013 Comput. Diagnosis, 2013: p. 86703I. https://doi.org/10.1117/12.2007259.

[93] A.R. Abdel-Dayem, M.R. El-Sakka, A. Fenster, Watershed segmentation for carotid artery ultrasound images, 3rd ACS/IEEE Int. Conf. Comput. Syst. Appl. 2005. 2005 (2005) 735-742. https://doi.org/10.1109/AICCSA.2005.1387120.

[94] K. Saini, M.L. Dewal, M. Rohit, Ultrasound Imaging and Image Segmentation in the area of Ultrasound : A Ultrasound Imaging and Image Segmentation in the area of Ultrasound: A Review, (2010).

[95] D.D.B. Carvalho, Z. Akkus, S.C.H. van den Oord, A.F.L. Schinkel, A.F.W. van der Steen, W.J. Niessen, J.G. Bosch, S. Klein, Lumen Segmentation and Motion Estimation in B-Mode and Contrast-Enhanced Ultrasound Images of the Carotid Artery in Patients With Atherosclerotic Plaque, IEEE Trans. Med. Imaging. 34 (2015) 983-993. https://doi.org/10.1109/TMI.2014.2372784.

[96] F. Benzarti, H. Amiri, Speckle Noise Reduction in Medical Ultrasound Images, Proc. 9th WSEAS Int. Conf. Signal, Speech Image Process. SSIP '09, Proc. 9th WSEAS Int. Conf. Multimedia, Internet Video Technol. MIV '09. (2013) 126-131. http://arxiv.org/abs/1305.1344.

[97] F. Molinari, K.M. Meiburger, L. Saba, U.R. Acharya, G. Ledda, G. Zeng, S.Y.S. Ho, A.T. Ahuja, S.C. Ho, A. Nicolaides, J.S. Suri, Ultrasound IMT measurement on a multi-ethnic and multi-institutional database: Our review and experience using four fully automated and one semi-automated methods, Comput. Methods Programs Biomed. 108 (2012) 946-960. https://doi.org/10.1016/j.cmpb.2012.05.008.

[98] E.G. Sifakis, S. Golemati, Robust carotid artery recognition in longitudinal B-mode ultrasound images, IEEE Trans. Image Process. 23 (2014) 3762-3772. https://doi.org/10.1109/TIP.2014.2332761.

[99] F. Molinari, G. Zeng, J.S. Suri, An Integrated Approach to Computer-Based Automated Tracing and Its Validation for 200 Common Carotid Arterial Wall Ultrasound Images, J. Ultrasound Med. 29 (2010) 399-418. https://doi.org/10.7863/jum.2010.29.3.399.

[100] P. Krishna Kumar, T. Araki, J. Rajan, L. Saba, F. Lavra, N. Ikeda, A.M. Sharma, S. Shafique, A. Nicolaides, J.R. Laird, A. Gupta, J.S. Suri, Accurate lumen diameter measurement in curved vessels in carotid ultrasound: an iterative scale-space and spatial transformation approach, Med. Biol. Eng. Comput. 55 (2017) 1415-1434. https://doi.org/10.1007/s11517-016-1601-y.

[101] R. Rocha, J. Silva, A. Campilho, Automatic detection of the carotid lumen axis in B-mode ultrasound images, Comput. Methods Programs Biomed. 115 (2014) 110-118. https://doi.org/10.1016/j.cmpb.2014.04.004.

[102] T. Araki, P.K. Kumar, H.S. Suri, N. Ikeda, A. Gupta, L. Saba, J. Rajan, F. Lavra, A.M. Sharma, S. Shafique, A. Nicolaides, J.R. Laird, J.S. Suri, Two Automated Techniques for Carotid Lumen Diameter Measurement: Regional versus Boundary Approaches, J. Med. Syst. 40 (2016). https://doi.org/10.1007/s10916016-0543-0.

[103] J.F. Polak, M. Szklo, D.H. O'Leary, Associations of Coronary Heart Disease with Common Carotid Artery Near and Far Wall Intima-Media Thickness: The Multi-Ethnic Study of Atherosclerosis, J. Am. Soc. Echocardiogr. 28 (2015) 1114-1121. https://doi.org/10.1016/j.echo.2015.04.001.

[104] J.F. Polak, W.S. Post, J.J. Carr, M. Szklo, D.H. O'Leary, Associations of Common Carotid IntimaMedia Thickness with Coronary Heart Disease Risk Factors and Events Vary with Distance from the Carotid Bulb, J. Am. Soc. Echocardiogr. 27 (2014) 991-997. https://doi.org/10.1016/j.echo.2014.04.019.

[105] Pierre-Jean Touboul;Patrizio Prati;Pierre-Yves Scarabin;Valerie Adrai;Emmanuel Thibout; and Pierre Ducimetiere, Use of monitoring software to improve the measurement of carotid wall thickness by B-mode imaging, (1992) S37-S41.

[106] C. Liguori, A. Paolillo, A. Pietrosanto, An automatic measurement system for the evaluation of carotid intima-media thickness, IEEE Trans. Instrum. Meas. 50 (2001) 1684-1691. 
https://doi.org/10.1109/19.982968.

[107] G. Zahnd, K. Kapellas, M. van Hattem, A. van Dijk, A. Serusclat, P. Moulin, A. van der Lugt, M. Skilton, M. Orkisz, A Fully-Automatic Method to Segment the Carotid Artery Layers in Ultrasound Imaging: Application to Quantify the Compression-Decompression Pattern of the Intima-Media Complex During the Cardiac Cycle, Ultrasound Med. Biol. 43 (2017) 239-257. https://doi.org/10.1016/j.ultrasmedbio.2016.08.016.

[108] Y. Zhou, X. Cheng, X. Xu, E. Song, Dynamic programming in parallel boundary detection with application to ultrasound intima-media segmentation, Med. Image Anal. 17 (2013) 892-906. https://doi.org/10.1016/j.media.2013.05.009.

[109] F. Faita, V. Gemignani, E. Bianchini, C. Giannarelli, L. Ghiadoni, M. Demi, Real-time Measurement System for Evaluation of the Carotid Intima-Media Thickness With a Robust Edge Operator, J. Ultrasound Med. 27 (2008) 1353-1361. https://doi.org/10.7863/jum.2008.27.9.1353.

[110] A.C. Rossi, P.J. Brands, A.P.G. Hoeks, Automatic Localization of Intimal and Adventitial Carotid Artery Layers with Noninvasive Ultrasound: A Novel Algorithm Providing Scan Quality Control, Ultrasound Med. Biol. 36 (2010) 467-479. https://doi.org/10.1016/j.ultrasmedbio.2009.12.007.

[111] S. Golemati, J. Stoitsis, T. Balkizas, K.S. Nikita, Comparison of B-mode, M-mode and Hough transform methods for measurement of arterial diastolic and systolic diameters, (2006) 1758-1761. https://doi.org/10.1109/iembs.2005.1616786.

[112] S. Golemati, J. Stoitsis, E.G. Sifakis, T. Balkizas, K.S. Nikita, Using the Hough Transform to Segment Ultrasound Images of Longitudinal and Transverse Sections of the Carotid Artery, Ultrasound Med. Biol. 33 (2007) 1918-1932. https://doi.org/10.1016/j.ultrasmedbio.2007.05.021.

[113] C.P. Loizou, C.S. Pattichis, M. Pantziaris, T. Tyllis, A. Nicolaides, Snakes based segmentation of the common carotid artery intima media, Med. Biol. Eng. Comput. 45 (2007) 35-49. https://doi.org/10.1007/s11517-006-0140-3.

[114] N. Santhiyakumari, P. Rajendran, M. Madheswaran, S. Suresh, Detection of the intima and media layer thickness of ultrasound common carotid artery image using efficient active contour segmentation technique, Med. Biol. Eng. Comput. 49 (2011) 1299-1310. https://doi.org/10.1007/s11517-011-0800-9.

[115] F. Destrempes, J. Meunier, M.F. Giroux, G. Soulez, G. Cloutier, Segmentation in ultrasonic B-mode images of healthy carotid arteries using mixtures of Nakagami distributions and stochastic optimization, IEEE Trans. Med. Imaging. 28 (2009) 215-229. https://doi.org/10.1109/TMI.2008.929098.

[116] F. Molinari, G. Zeng, J.S. Suri, Inter-Greedy Technique for Fusion of Different Segmentation Strategies Leading to High-Performance Carotid IMT Measurement in Ultrasound Images, in: Atheroscler. Dis. Manag., Springer New York, New York, NY, 2011: pp. 253-279. https://doi.org/10.1007/978-1-4419-7222$4 \_10$.

[117] F. Molinari, G. Zeng, J.S. Suri, Greedy Technique and Its Validation for Fusion of Two Segmentation Paradigms Leads to an Accurate Intima-Media Thickness Measure in Plaque Carotid Arterial Ultrasound, J. Vasc. Ultrasound. 34 (2018) 63-73. https://doi.org/10.1177/154431671003400201.

[118] F. Molinari, G. Zeng, J.S. Suri, Inter-greedy technique for fusion of different segmentation strategies leading to high-performance carotid IMT measurement in ultrasound images, Atheroscler. Dis. Manag. (2011) 253-279. https://doi.org/10.1007/978-1-4419-7222-4_10.

[119] D.E. Ilea, C. Duffy, L. Kavanagh, A. Stanton, P.F. Whelan, Fully automated segmentation and tracking of the intima media thickness in ultrasound video sequences of the common carotid artery, IEEE Trans. Ultrason. Ferroelectr. Freq. Control. 60 (2013) 158-177. https://doi.org/10.1109/TUFFC.2013.2547. 
[120] R.M. Menchon-Lara, M.C. Bastida-Jumilla, J. Morales-Sanchez, J.L. Sancho-Gomez, Automatic detection of the intima-media thickness in ultrasound images of the common carotid artery using neural networks, Med. Biol. Eng. Comput. 52 (2014) 169-181. https://doi.org/10.1007/s11517-013-1128-4.

[121] A.K. Patel, H.S. Suri, J. Singh, D. Kumar, S. Shafique, A. Nicolaides, S.K. Jain, L. Saba, A. Gupta, J.R. Laird, A. Giannopoulos, J.S. Suri, A Review on Atherosclerotic Biology, Wall Stiffness, Physics of Elasticity, and Its Ultrasound-Based Measurement, Curr. Atheroscler. Rep. 18 (2016). https://doi.org/10.1007/s11883-016-0635-9.

[122] F. Molinari, G. Zeng, J.S. Suri, A state of the art review on intima-media thickness (IMT) measurement and wall segmentation techniques for carotid ultrasound, Comput. Methods Programs Biomed. 100 (2010) 201-221. https://doi.org/10.1016/j.cmpb.2010.04.007.

[123] B. Ihnatsenka, A.P. Boezaart, Ultrasound: Basic understanding and learning the language, Int. J. Shoulder Surg. 4 (2010) 55-62. https://doi.org/10.4103/0973-6042.76960.

[124] B. Schmauch, P. Herent, P. Jehanno, O. Dehaene, C. Saillard, C. Aube, A. Luciani, N. Lassau, S. Jegou, Diagnosis of focal liver lesions from ultrasound using deep learning, Diagn. Interv. Imaging. 100 (2019) 227-233. https://doi.org/10.1016/j.diii.2019.02.009.

[125] B.Q. Huynh, H. Li, M.L. Giger, Digital mammographic tumor classification using transfer learning from deep convolutional neural networks, J. Med. Imaging. 3 (2016) 034501. https://doi.org/10.1117/1.jmi.3.3.034501.

[126] N. Hatipoglu, G. Bilgin, Cell segmentation in histopathological images with deep learning algorithms by utilizing spatial relationships, Med. Biol. Eng. Comput. 55 (2017) 1829-1848. https://doi.org/10.1007/s11517-017-1630-1.

[127] W. Bai, M. Sinclair, G. Tarroni, O. Oktay, M. Rajchl, G. Vaillant, A.M. Lee, N. Aung, E. Lukaschuk, M.M. Sanghvi, F. Zemrak, K. Fung, J.M. Paiva, V. Carapella, Y.J. Kim, H. Suzuki, B. Kainz, P.M. Matthews, S.E. Petersen, S.K. Piechnik, S. Neubauer, B. Glocker, D. Rueckert, Automated cardiovascular magnetic resonance image analysis with fully convolutional networks, J. Cardiovasc. Magn. Reson. 20 (2018) 1-12. https://doi.org/10.1186/s12968-018-0471-x.

[128] J. Wang, H. Ding, F.A. Bidgoli, B. Zhou, C. Iribarren, S. Molloi, P. Baldi, Detecting Cardiovascular Disease from Mammograms with Deep Learning, IEEE Trans. Med. Imaging. 36 (2017) 1172-1181. https://doi.org/10.1109/TMI.2017.2655486.

[129] A. Jamthikar, D. Gupta, N.N. Khanna, L. Saba, J.R. Laird, J.S. Suri, Cardiovascular/stroke risk prevention: A new machine learning framework integrating carotid ultrasound image-based phenotypes and its harmonics with conventional risk factors, Indian Heart J. (2020) 0-6. https://doi.org/10.1016/j.ihj.2020.06.004.

[130] M. Biswas, V. nkatanareshbabu Kuppili, D.R. Edla, H.S. Suri, L. Saba, R.T. Marinhoe, J.M. Sanches, J.S. Suri, Symtosis: A liver ultrasound tissue characterization and risk stratification in optimized deep learning paradigm, Comput. Methods Programs Biomed. 155 (2018) 165-177. https://doi.org/10.1016/j.cmpb.2017.12.016.

[131] V. Kuppili, M. Biswas, A. Sreekumar, H.S. Suri, L. Saba, D.R. Edla, R.T. Marinhoe, J.M. Sanches, J.S. Suri, Extreme Learning Machine Framework for Risk Stratification of Fatty Liver Disease Using Ultrasound Tissue Characterization, J. Med. Syst. 41 (2017) 152. https://doi.org/10.1007/s10916-017-0797-1.

[132] R. Hemalatha, V. Vijaybaskar, T. Thamizhvani, Automatic localization of anatomical regions in medical ultrasound images of rheumatoid arthritis using deep learning, Proc. Inst. Mech. Eng. Part H J. Eng. Med. (2019) 095441191984574. https://doi.org/10.1177/0954411919845747.

[133] R. Poplin, A. V. Varadarajan, K. Blumer, Y. Liu, M. V. McConnell, G.S. Corrado, L. Peng, D.R. Webster, Prediction of cardiovascular risk factors from retinal fundus photographs via deep learning, Nat. Biomed. Eng. 2 (2018) 158-164. https://doi.org/10.1038/s41551-018-0195-0. 
[134] J. Wang, H. Ding, F.A. Bidgoli, B. Zhou, C. Iribarren, S. Molloi, P. Baldi, Detecting Cardiovascular Disease from Mammograms With Deep Learning, IEEE Trans. Med. Imaging. 36 (2017) 1172-1181. https://doi.org/10.1109/TMI.2017.2655486.

[135] N. Tajbakhsh, J.Y. Shin, R.T. Hurst, C.B. Kendall, J. Liang, Automatic Interpretation of Carotid Intima-Media Thickness Videos Using Convolutional Neural Networks, in: Deep Learn. Med. Image Anal., 1st ed., Elsevier, 2017: pp. 105-131. https://doi.org/10.1016/B978-0-12-810408-8.00007-9.

[136] K. Lekadir, A. Galimzianova, A. Betriu, M. del Mar Vila, L. Igual, D.L. Rubin, E. Fernandez, P. Radeva, S. Napel, A Convolutional Neural Network for Automatic Characterization of Plaque Composition in Carotid Ultrasound, IEEE J. Biomed. Heal. Informatics. 21 (2017) 48-55. https://doi.org/10.1109/JBHI.2016.2631401.

[137] A. Kumar Patel, S. Kumar Jain, Arterial Parameters and Elasticity Estimation in Common Carotid Artery Using Deep Learning Approach, Int. J. Image, Graph. Signal Process. 11 (2019) 18-28. https://doi.org/10.5815/ijigsp.2019.11.03.

[138] E.A. Melnikova, I. V. Avdeeva, V.E. Oleynikov, Echo-Tracking is a novel technology to assess structural and functional properties of carotid arteries (review), Sovrem. Tehnol. v Med. 8 (2016) 119-127. https://doi.org/10.17691/stm2016.8.2.16.

[139] I.S. Mackenzie, Assessment of arterial stiffness in clinical practice, QJM. 95 (2002) 67-74. https://doi.org/10.1093/qjmed/95.2.67.

[140] T. Miyoshi, H. Ito, Assessment of Arterial Stiffness Using the Cardio-Ankle Vascular Index, Pulse. 4 (2016) 11-23. https://doi.org/10.1159/000445214.

\section{Biographies}

Shanu Nizarudeen is a research scholar at NICHE, Kumaracoil, Tamilnadu. He is an assistant professor in the Depart

Ganesh R. Shunmugavel, PhD is an associate professor working with NICHE, Kumaracoil, Tamilnadu, India. He has 